\title{
Trajectory Optimization in Robotic Applications Survey of Recent Developments
}

\author{
Eyad Almasri ${ }^{1, *}$ and Mustafa Kemal Uyguroğlu ${ }^{1}$
}

1 Department of Electrical and Electronic Engineering, Eastern Mediterranean University, Famagusta North Cyprus, Mersin 10 Turkey; infoee@emu.edu.tr; Tel.:+90 3926301301

* Correspondence: eyad.almasri@emu.edu.tr; Tel.:+90 5338872135

\begin{abstract}
Trajectory Optimization (TO) is the sequence of processes that are considered in order to produce the best path that mends the overall performance or reduces the consumption of the resources where the restriction system remains maintained. In this survey, an inclusive review of the latest advancements in modeling and optimization of trajectory generation in robotic applications will be discussed broadly. In recent times, numerous studies have employed optimal control techniques involving direct and indirect methods in order to convert the authentic Trajectory Optimization problem into a constrained parameter optimization problem. Moreover, a huge variety of optimization algorithms such as Genetic Algorithms (GA), Simulated Annealing (SA), Sequential Quadratic Programming (SQP), and Particle Swarm Optimization (PSO) are used aiming to find the optimal solutions for trajectory planning. It is observable that, minimizing the jerk, energy consumption, and execution time among the most widely used design objectives, on the other hand, the robot's joints configurations and the motor torques are the most used design variables. This paper aims to review the fundamental techniques and their coincident robotic applications in the field of trajectory optimization aiming to afford some steering for related researchers.
\end{abstract}

Keywords: Robotics; Optimization; Optimal Control (OC); Trajectory planning; Dynamic Transcription methods

\section{Introduction}

An unbounded number of applications use the techniques of trajectory generation aiming to speculate, plane and formalize the optimum path especially in robotics applications which are the subject of this research. Important applications in robotics such as the robots that use legs [1-4], navigation robots [5-12] and robot's manipulators [13-23] are in dire need of using the techniques of optimal trajectory in order to optimize the usage of these applications according to the estimates of peripheral conditions.

From a broader perspective, it is possible to count the problem of finding the optimal path as one category of techniques that seek to find the optimal control which is interested in determining the best control option to fulfill goals are required [24]. Closed circuit solution and Open circuit solution are among the most famous solutions to the problem of finding the optimal control [25]. However, although the closed circuit solution is more accurate and comprehensive but it is not suitable when the studied system involves a high number of degrees of freedom, a quadruped robot encompasses a 12 servo motors will lead to 24 dimensions' state in control function and there is no way to deal with and solve the problem of optimal control using closed loop with such number of degrees of freedom. As a result of this discussion we can consider the open loop solution, the control is a function only of time, to the problem of finding the optimal control in case of robotics applications is quite convenient [26].

Historically, Brachchystochrone issue [27], a search process for the twist that gives the rapid decline when a pellet skid between two points different in height and uneven, represents the starting point of human thinking in the search for the optimal path between 
two points. However, the scientist Johann Bernoulli presented in 1969 a revolutionary vision based on the shape of the path to solve this problem using the calculus of variation [28], the sort of math specialized to locate the maximum and minimum using the trivial alteration of the functions. Subsequently, with the rise of the digital revolution, the computing devices opened a new era of making a trajectory generation theories applicable in actual life problems.

Aviation and rocket applications were the first to use the strategies of open control optimization aiming to increase the overall performance. The path of the missile is affected by two factors, the first is the rocket thrust and the second is the combination of air forces applied to the surface of the extruded body. Several conditions affect the second factor such as launch angle, the shape of the outer surface and the rise-drop schedule. However, each set of specific shape missile, required execution, and constraints system represents a special case of trajectory optimization problem with specific specifications [29]. In regard to jet aircraft, the trajectory optimization techniques were able to provide a special schedule used by pilots organize the speed according to the height of the aircraft [30]. Moreover, Quadrotor helicopter control systems have benefited pointedly through the use of the techniques of trajectory generation. An engineering team in Pennsylvania university performed a trajectory generated based model authorize the Quadcopter to maneuver over a ring after giving it an initial push velocity [31]. Another stunning quadrotor application based on path planning algorithms comprises two quadrocopters one of them sling a pendulum and the other pick it up [32]. In the industrial field, paramount applications use optimal trajectory algorithms such as a supervision control of chemical processes in factories [33]. When discussing robot applications, talk is incomplete without taking the trajectory planning methods into account. The rest of this research will focus on the use impact of the optimal path trajectory in the various robot fields.

\section{Classification of Robotics System}

There are many theories on how robots are categorized. However, the most literature classified the robots in terms of its applications and the type of locomotion and kinematics. Both categories will be discussed about regarding robotic trajectory optimization.

\subsection{Classification According to the Applications of the Robot Systems}

Unlimited number of tasks that can be executed by robots. However, robots can be classified in terms of performing tasks

1. Industrial Robots: Including the robots that function in manufacturing environment as the robots in [36-38];

2. Medical Robots: The group of robots operating in medical facilities such as surgical robots. Some of these robots exist in [42-43];

3. Service Robots: Robots used in researches are classified as service robots [8, 44];

4. Space Robots: Any Robot functions beyond earth's atmosphere is space robots [45];

The following table summarizes important researches handling the trajectory optimization in robotic field and classifies these researches according to the type of the robot applications.

48

Table 1. Classification according to the system application

\begin{tabular}{lll}
\hline $\begin{array}{c}\text { System ap- } \\
\text { plication }\end{array}$ & References & \multicolumn{1}{c}{ Remarks } \\
\hline & & - Attempt to improve the energy efficiency of the robot. \\
\multirow{3}{*}{$\begin{array}{l}\text { Industrial } \\
\text { Robots }\end{array}$} & Paes et al (2014) & - ACCADO-toolkit used for trajectory optimization. \\
\cline { 2 - 4 } & & - The experiments carried on IRB1600 industrial ABB robot. \\
\cline { 2 - 4 } & Abu-Dakka et al (2013) & - Minimizing the execution time between two configurations. \\
\hline
\end{tabular}




\begin{tabular}{|c|c|c|}
\hline & & $\begin{array}{l}\text { - An INDIRECT approach used for the optimality. } \\
\text { - } \quad \text { PUMA } 560 \text { is tested in this research. }\end{array}$ \\
\hline & Gasparetto et al (2010) & $\begin{array}{l}\text { - Minimize the execute time and the jerk alongside the trajectory. } \\
\text { - Comparison between third-order and fifth-order B spline. } \\
\text { - Gantry robot with spherical wrist is tested in this research. }\end{array}$ \\
\hline & Jin et al (2015) & $\begin{array}{l}\text { - A dynamic modeling is used to solve TO problem. } \\
\text { - Hadamard's inequality used aiming to define the objective } \\
\text { - Staubli TX-90 used to test the optimization novel. }\end{array}$ \\
\hline & Valente et al (2017) & $\begin{array}{l}\text { - Minimize execution time. } \\
\text { - TO problem constructed by non-optimal control formulation. } \\
\text { - The approach is valid for all kinematic-chain based robot. }\end{array}$ \\
\hline \multirow{3}{*}{$\begin{array}{l}\text { Medical } \\
\text { Robots }\end{array}$} & Gupta et al (2015) & $\begin{array}{l}\text { - Find the optimal trajectory for the MIRS robot } \\
\text { - The TO problem solved using several metaheuristics algorithms } \\
\text { - Artificial Bee Colonization algorithm showed the best result. }\end{array}$ \\
\hline & Jiang et al (2017) & $\begin{array}{l}\text { - DTM algorithm is used to align actual and optimum trajectory. } \\
\text { - } \quad \text { PSO used to solve the optimization problematic. } \\
\text { - } \quad \text { MIRS robot utilized to estimate the algorithm performance }\end{array}$ \\
\hline & Poya et al (2020) & $\begin{array}{l}\text { - A PUMA manipulator is to be used with custom regenerative drives } \\
\text { - A standard robust passivity based control approach is used for } \\
\text { optimal trajectories tracking } \\
\text { - The optimization problem modeled to find point-to point } \\
\text { trajectories maximizing energy }\end{array}$ \\
\hline \multirow{3}{*}{$\begin{array}{l}\text { Service Ro- } \\
\text { bots }\end{array}$} & Celeste et al (2009) & $\begin{array}{l}\text { - TO problem solved using Cross Entropy method } \\
\text { - The robot state is defined using map-based localization. }\end{array}$ \\
\hline & De Magistris et al (2017) & $\begin{array}{l}\text { - The TO problem formulated as a Quadratic program. } \\
\text { - Minimize the energy consumption. } \\
\text { - } \quad \text { Find the smooth trajectory under each foot. }\end{array}$ \\
\hline & Marko et al (2020) & $\begin{array}{l}\text { - TO performed on the robot combining legs and wheels. } \\
\text { - The optimization problem formalized to be solved online using } \\
\text { predictive control strategies } \\
\text { - The method used is robust against unpredicted disturbances }\end{array}$ \\
\hline Space Robots & Chu et al (2017) & $\begin{array}{l}\text { - Minimize the fuel consumption. } \\
\text { - TO problem formulated as optimal control problem. } \\
\text { - Gauss Pseudospectral method used for transcription. }\end{array}$ \\
\hline
\end{tabular}

2.2. Classification According to the type of locomotion of the robot systems

Robot systems could be classified in terms of the movement manner as follow:

1. Stationary Robots: This type of robot is installed in fixed place. Mainly, there is an arm can manipulate around the fixed part of the robot [13-23];

2. Wheeled Robots: Characterized as being able to maneuver through wheels [5-12];

3. Legged Robots: Includes four main varieties; bipeds, quadrupeds, hexapods and octopods [1-4];

4. Swarm Robots: Independent robots with the same form and design, characterized by being able to perform functions in a harmonious and participatory manner [48-50];

The following table summarizes important researches handling the trajectory optimization in robotic field and classifies these researches according to the type of the robot locomotion. 
Table 2. Classification according to the type of the robot locomotion

\begin{tabular}{|c|c|c|}
\hline $\begin{array}{c}\text { System } \\
\text { locomotion type }\end{array}$ & References & Remarks \\
\hline \multirow{12}{*}{ Stationary Robots } & Menasri et al (2015) & $\begin{array}{l}\text { - TO problem formulated by bilevel optimization technique. } \\
\text { - GA utilized aiming to solve the optimization problem. } \\
\text { - The technique is valid for redundant manipulator. }\end{array}$ \\
\hline & Gregory et al (2012) & $\begin{array}{l}\text { - TO problem formulated as an optimal control problem. } \\
\text { - Finding the optimal energy consumption. } \\
\text { - Two Revolute planar manipulator used for the experiments. } \\
\text { - The TO problem modeled with Holonomic Constraints. } \\
\text { - Indirect method is used to achieve the discretization. }\end{array}$ \\
\hline & Böck et al (2016) & $\begin{array}{l}\text { - Optimal control formula is used to model the TO problem. } \\
\text { - PSOPT simulator utilized to solve the OC problem. } \\
\text { - Fmincon is used to solve the static optimization problem. } \\
\text { - The algorithms presented are valid at Staubli TX60L. }\end{array}$ \\
\hline & Wu et al (2016) & $\begin{array}{l}\text { - Minimize the Jerk of the } 10 \text { DOF serial articulated robot. } \\
\text { - TO problem formulated using alternative method. } \\
\text { - GA applied to catch the global solution of the TO problem. }\end{array}$ \\
\hline & Shareef et al (2014) & $\begin{array}{l}\text { - Finding the optimum trajectory energy consumption. } \\
\text { - TO problem is solved as dynamic program. } \\
\text { - The validity of the technique tested at DELTA robot. }\end{array}$ \\
\hline & Kucuk (2017) & $\begin{array}{l}\text { - TO problem formulated by non-optimal based model. } \\
\text { - PSO utilized to find the minimum time smooth trajectory. } \\
\text { - Cubic spline scheme used for interpolation. } \\
\text { - PUMA robot used to test the techniques. }\end{array}$ \\
\hline & Števo et al (2014) & $\begin{array}{l}\text { - Minimizing time, energy consumption and joints rotation. } \\
\text { - TO problem modeled by alternative formula. } \\
\text { - GA is used to find the optimal trajectory. }\end{array}$ \\
\hline & Elshabasy et al (2017) & $\begin{array}{l}\text { - Minimize the power consumption. } \\
\text { - Planar redundant robot used to test the OT Techniques. } \\
\text { - Hybrid method consisting of GA and Fmincon is utilized. }\end{array}$ \\
\hline & Cao et al (2016). & $\begin{array}{l}\text { - RRR redundant robotic arm stated for testing the algorithm. } \\
\text { - TO problem formulated by geometric techniques. } \\
\text { - The optimization proposed using hybrid technique. } \\
\text { - Crossover, Mutation PSO along with interior point method. }\end{array}$ \\
\hline & Zachary et al (2019) & $\begin{array}{l}\text { - Trajectory optimization based on direct collocation method. } \\
\text { - Approximate invariant funnel method used along the trajectory } \\
\text { in order to achieve the optimality. }\end{array}$ \\
\hline & Matteo et al (2019) & $\begin{array}{l}\text { - Kinematic decoupling through via points used to generate the } \\
\text { optimal trajectory of the redundant serial manipulator }\end{array}$ \\
\hline & Poya et al (2020) & $\begin{array}{l}\text { - A PUMA manipulator used with custom regenerative drives } \\
\text { - A standard robust passivity based control approach is used for } \\
\text { optimal trajectories tracking } \\
\text { - The optimization problem modeled to find point-to point } \\
\text { trajectories maximizing energy }\end{array}$ \\
\hline \multirow{2}{*}{ Wheeled Robots } & Walambe et al (2016) & $\begin{array}{l}\text { - TO problem solved by spline based approach. } \\
\text { - The prototype car modeled as nonholonomic system. } \\
\text { - Differential flatness used to define the steer control line. }\end{array}$ \\
\hline & Celeste et al (2009) & $\begin{array}{l}\text { - Cross Entropy method utilized aiming to solve TO problem. } \\
\text { - Geometric map is used to define the mobile robot positions. }\end{array}$ \\
\hline
\end{tabular}




\begin{tabular}{|c|c|}
\hline Kalmár-Nagy (2016) & $\begin{array}{l}\text { - path optimal solutions have done using SNOPT function } \\
\text { - Dynamic inversion based method presented for TG }\end{array}$ \\
\hline Li et al (2015) & $\begin{array}{l}\text { - TO problem formulated using optimal control based scheme. } \\
\text { - Minimize the execution time. } \\
\text { - The optimization is solved using dynamic program. }\end{array}$ \\
\hline Gilimyanov et al (2008) & $\begin{array}{l}\text { - Improve Bspline of paths constructed by noisy control points } \\
\text { - The improvement is reached by varying the control points. } \\
\text { - The measurements error is found by solve standard QP }\end{array}$ \\
\hline Vale et al (2014) & $\begin{array}{l}\text { - TO problem modeled as non-control optimization problem } \\
\text { - Maximize the clearance of the obstacles. } \\
\text { - Suitable for dangerous environment. }\end{array}$ \\
\hline Mac et al (2017) & $\begin{array}{l}\text { - Multi-objective path planning. } \\
\text { - Minimize the path length } \\
\text { - Maximize the smoothness. } \\
\text { - Dijkstra's algorithm used to find a collision-free trajectory. } \\
\text { - PSO is utilized to obtain the optimized trajectory. }\end{array}$ \\
\hline Hui et al (2019) & $\begin{array}{l}\text { - Ant colony optimization algorithm used in this research. } \\
\text { - Turning point optimization algorithm proposed to solve the } \\
\text { trajectory optimization. } \\
\text { - For easier tracking control of the mobile robot B-spline path } \\
\text { smoother is presented. }\end{array}$ \\
\hline Sarkar et al (2015) & $\begin{array}{l}\text { - } 8 \text { DOF humanoid robot. } \\
\text { - Optimize the gait of the robot. } \\
\text { - } \text { TO problem formulated geometrically. } \\
\text { - GA is used to find the optimality. } \\
\text { - Lagrange-Euler method used to model the dynamic system. }\end{array}$ \\
\hline Sun et al (2015) & $\begin{array}{l}\text { - Optimize the trajectory of bipedal walking robot. } \\
\text { - TO problem modeled as Optimal Control problem. } \\
\text { - Exact penalty function algorithm used to solve OC problem. }\end{array}$ \\
\hline Aoustin et al (2013) & $\begin{array}{l}\text { - Planar biped robot with four-bar knees. } \\
\text { - A sthenic criteria is used to solve the TO problem. }\end{array}$ \\
\hline Koch et al (2012) & $\begin{array}{l}\text { - Humanoid robot HRP2 with } 36 \text { DOF and } 30 \text { actuators. } \\
\text { - TO modeled as an optimal control. } \\
\text { - Minimize torque squared. } \\
\text { - Maximize forward velocities. } \\
\text { - The OC problem solved by framework MUSCODII }\end{array}$ \\
\hline Chen et al (2016) & $\begin{array}{l}\text { - Generate optimized walking trajectories for Bipedal robot } \\
\text { - The cost function defined as a sthenic criterion. } \\
\text { - SQP is used to solve the optimization problem. }\end{array}$ \\
\hline De Magistris et al (2017). & $\begin{array}{l}\text { - Minimize the energy consumption. } \\
\text { - Quadratic program used to formulate the TO problem. }\end{array}$ \\
\hline Lim et al (2014) & $\begin{array}{l}\text { - Efficient trajectory stair walking for humanoid robot. } \\
\text { - Genetic algorithm is used to generate OT. }\end{array}$ \\
\hline Romeo et al (2018) & $\begin{array}{l}\text { - Trajectory Optimization of Biped Robot performed online } \\
\text { - Wrench Polytope (AWP) and the Feasible Wrench Polytope } \\
\text { (FWP) introduced to study the stability and the actuation } \\
\text { consistency of a given motion planning. } \\
\text { - Feasibility factor adapted based on AWP and FWP to improve } \\
\text { the the process of trajectory optimization }\end{array}$ \\
\hline In-Seok et al (2019) & - Humanoid used in this research \\
\hline
\end{tabular}

Legged Robots

\section{Kalmár-Nagy (2016)}

Li et al (2015)

Gilimyanov et al (2008)

Vale et al (2014)

Hui et al (2019)

Sarkar et al (2015)
- path optimal solutions have done using SNOPT function

- Minimize the execution time.

- Improve Bspline of paths constructed by noisy control points

- The measurements error is found by solve standard QP

- TO problem modeled as non-control optimization problem

- Multi-objective path planning.

- Minimize the path length

- Maximize the smoothness.

- Dijkstra's algorithm used to find a collision-free trajectory

- PSO is utilized to obtain the optimized trajectory.

- Ant colony optimization algorithm used in this research.

trajectory optimization.

For easier tracking control of the mobile robot B-spline path presented.

- Optimize the gait of the robot.

- TO problem formulated geometrically.

- GA is used to find the optimality.

- Lagrange-Euler method used to model the dynamic system.

- Optimize the trajectory of bipedal walking robot.

- TO problem modeled as Optimal Control problem.

- Exact penalty function algorithm used to solve OC problem

- Planar biped robot with four-bar knees

- A sthenic criteria is used to solve the TO problem.

- Humanoid robot HRP2 with 36 DOF and 30 actuators.

- The OC problem solved by framework MUSCODII

- Generate optimized walking trajectories for Bipedal robot

- The cost function defined as a sthenic criterion.

- Quadratic program used to formulate the TO problem.

- Efficient trajectory stair walking for humanoid robot.

- Genetic algorithm is used to generate OT.

- Trajectory Optimization of Biped Robot performed online (FWP) introduced to study the stability and the actuation consistency of a given motion planning.

improve

- Humanoid used in this research 


\begin{tabular}{|c|c|c|}
\hline & & $\begin{array}{l}\text { - The control input generated by capture point method } \\
\text { - Sliding mode controller used to follow the zero moment point }\end{array}$ \\
\hline & Wolfgang et al (2020) & $\begin{array}{l}\text { - Dynamic obstacle avoidance considered } \\
\text { - Harmonic potential field used for collision avoidance }\end{array}$ \\
\hline & Amir et al (2019) & $\begin{array}{l}\text { - Biped robot is used in this research } \\
\text { - Orthogonal Collocation used for trajectory optimization }\end{array}$ \\
\hline \multirow{4}{*}{ Swarm Robots } & Das et al (2016) & $\begin{array}{l}\text { - Clutter environment is considered. } \\
\text { - Optimize the trajectory of multi-robot } \\
\text { - An improved PSO is used. } \\
\text { - GSA algorithm used to improve exploration performance } \\
\text { - Minimize the energy consumption. }\end{array}$ \\
\hline & Asma et al (2017) & $\begin{array}{l}\text { - Multiple robot trajectory generation system. } \\
\text { - Dynamic Distributed PSO used to find the optimality. }\end{array}$ \\
\hline & Das et al (2016) & $\begin{array}{l}\text { - Multi robot path planning } \\
\text { - An improved gravitational search is proposed for TO }\end{array}$ \\
\hline & Oleiwi et al (2015). & $\begin{array}{l}\text { - Multi robots and multi objective path planning } \\
\text { - Trajectory for each robot generated in independent manner } \\
\text { - Modified GA with } \mathrm{A}^{*} \text { algorithm used for optimal results. }\end{array}$ \\
\hline
\end{tabular}

The trajectory optimization studies varied in terms of the nature of the analysis into experimental research, simulation research and combination of the experimental and simulation research. In the following table, the classification according to the type of research illustrated as follow

\begin{tabular}{|c|c|c|}
\hline type of Research & References & Remarks \\
\hline \multirow{7}{*}{ Simulation } & Gadaleta et al (2017) & $\begin{array}{l}\text { - Optimize the Energy consumption of the industrial robots. } \\
\text { - Propose simulation interface in Delmia robotic environment } \\
\text { - Automatic compute the motion parameters of the trajectory. }\end{array}$ \\
\hline & Gasparetto et al (2008) & $\begin{array}{l}\text { - Minimize the time and the jerk along the robot trajectory } \\
\text { - Cubic spline used for trajectory generation } \\
\text { - Proposed algorithm tested in iterative based simulator. }\end{array}$ \\
\hline & Ulrich et al (2016) & $\begin{array}{l}\text { - Robot based inspection system. } \\
\text { - Minimize the path along the trajectory. } \\
\text { - TO problem converted to salesman problem. } \\
\text { - Christof ides heuristic used to solve salesman problem. } \\
\text { - 3DCreate simulator software used to test the algorithm. }\end{array}$ \\
\hline & Hossain et al (2015) & $\begin{array}{l}\text { - Path planning for a mobile robot. } \\
\text { - Dynamic unknown environment. } \\
\text { - Minimize the path between two configurations. } \\
\text { - Non-optimal control formulation. } \\
\text { - Bacterial foraging optimization stated for optimality. }\end{array}$ \\
\hline & Pellegrinelli et al (2015) & $\begin{array}{l}\text { - Minimize the energy consumption. } \\
\text { - Pick-and-place assembly robot operation is investigated. } \\
\text { - The results presented using simulation software. }\end{array}$ \\
\hline & Baghli et al (2017) & $\begin{array}{l}\text { - Optimize the Trajectory of the arm manipulator. } \\
\text { - TO problem solved using Ant Colony algorithm. } \\
\text { - The stated technique tested using Matlab environment. }\end{array}$ \\
\hline & Shehata et al (2014) & $\begin{array}{l}\text { - Optimize varied parameters along the trajectory. } \\
\text { - Ensure safe navigation around the obstacles. }\end{array}$ \\
\hline
\end{tabular}




\begin{tabular}{|c|c|}
\hline & $\begin{array}{l}\text { - Non Dominated Sorting GA used for the optimality. } \\
\text { - Matlab is used to demonstrate the validity. }\end{array}$ \\
\hline Abu-Dakka et al (2013) & $\begin{array}{l}\text { - An INDIRECT approach } \\
\text { - PUMA } 560 \\
\text { - } \text { C++ used to determine numerical results } \\
\end{array}$ \\
\hline Gasparetto et al (2007) & $\begin{array}{l}\text { - } 6 \text { DOF open chain manipulator. } \\
\text { - SQP algorithm used to find the optimality. } \\
\text { - Minimize the energy and the jerk. } \\
\text { - Fifth-order-Bspline used to generate the trajectory. } \\
\text { - Matlab environment used to implement the simulation. }\end{array}$ \\
\hline Romeo et al (2018) & $\begin{array}{l}\text { - Trajectory Optimization of two Legged Robots performed online } \\
\text { - Feasibility factor adapted based on Wrench Polytope (AWP) and } \\
\text { the Feasible Wrench Polytope (FWP) to improve the the process of } \\
\text { trajectory optimization }\end{array}$ \\
\hline Yvain et al (2019) & $\begin{array}{l}\text { - Quadrupedal robots with actuated wheels considered } \\
\text { - Solve components of the base and the feet trajectories based on a } \\
\text { linear formulation of the zero moment point balance criterion } \\
\text { - The optimizer based on quadratic programming }\end{array}$ \\
\hline Amir et al (2019) & $\begin{array}{l}\text { - Biped robot is used in this research } \\
\text { - Orthogonal Collocation used for trajectory optimization }\end{array}$ \\
\hline Luke et al (2021) & $\begin{array}{l}\text { - Legged robot considered } \\
\text { - The approach susceptible to uncertainty } \\
\text { - It is suitable for utilizing robots on rough terrain } \\
\text { - The uncertainty modeled from the terrain and the corresponding } \\
\text { risk-sensitive objectives handled for contact-implicit trajectory } \\
\text { optimization. }\end{array}$ \\
\hline Paes et al (2014) & $\begin{array}{l}\text { - IRB1600 industrial ABB robot. } \\
\text { - ACCADO-toolkit used for trajectory optimization. } \\
\text { - Experiments placed to find the energy consumptions. }\end{array}$ \\
\hline Gasparetto et al (2010) & $\begin{array}{l}\text { - Minimizing the execution time and the jerk } \\
\text { - Gantry robot with spherical wrist. } \\
\text { - TO algorithm implemented using simulation software. } \\
\text { - Results tested experimentally using laboratory robot. }\end{array}$ \\
\hline Jin et al (2015) & $\begin{array}{l}\text { - Dynamic model used to solve TO problem. } \\
\text { - Simulation carried out to verify the proposed algorithm. } \\
\text { - Laboratory experiments used Staubli TX-90 robot. }\end{array}$ \\
\hline Walambe et al (2016) & $\begin{array}{l}\text { - Spline based approach to solve TO problem. } \\
\text { - Swift2Drft radio controlled vehicle used for experiments. } \\
\text { - Proposed algorithm carried out using matlab simulation. }\end{array}$ \\
\hline Kalmár-Nagy (2016) & $\begin{array}{l}\text { - SNOPT function used to solve the TO problem. } \\
\text { - TG solved using Dynamic inversion based method. } \\
\text { - MATLAB simulation used to run SNOPT toolbox. } \\
\text { - } \text { Four wheeled Omnidirectional vehicles used in experiments }\end{array}$ \\
\hline Sarkar et al (2015) & $\begin{array}{l}\text { - Optimize the gait of the biped robot. } \\
\text { - GA is used to find the TO. } \\
\text { - Dynamic system modeled using Lagrange-Euler method } \\
\text { - Simulation for finding OT for biped is done in Matlab. } \\
\text { - Results carried out experimentally using } 8 \text { DOF biped } \\
\text { - The Used Biped developed by bioloid premium kit. }\end{array}$ \\
\hline
\end{tabular}




\begin{tabular}{|c|c|}
\hline DeMagistris et al (2017) & $\begin{array}{l}\text { - Minimize the energy consumption. } \\
\text { - Walking gait is to be optimized } \\
\text { - HRP-4 humanoid used to validate the proposed algorithm. } \\
\text { - FEM simulation to model the contact e ground-sole contact. }\end{array}$ \\
\hline Jan et al (2019) & $\begin{array}{l}\text { - Legged robot considered. } \\
\text { - The optimization solver has the ability to freely evolution between } \\
\text { open, closed, and sliding contact states along the path. } \\
\text { - The trajectory optimization method can detect stepping motions } \\
\text { without predefined contact schedule }\end{array}$ \\
\hline Hui et al (2019) & $\begin{array}{l}\text { - Ant colony optimization algorithm used in this research } \\
\text { - Turning point optimization algorithm proposed to solve the } \\
\text { trajectory optimization } \\
\text { - For easier tracking control of the mobile robot B-spline path } \\
\text { smoother is presented. }\end{array}$ \\
\hline Poya et al (2020) & $\begin{array}{l}\text { - A PUMA manipulator used with custom regenerative drives. } \\
\text { - A standard robust passivity based control approach is used for } \\
\text { optimal trajectories tracking. } \\
\text { - The optimization problem modeled to find point-to point } \\
\text { trajectories maximizing energy. }\end{array}$ \\
\hline Marko et al (2020) & $\begin{array}{l}\text { - Wheeled-legged robot considered. } \\
\text { - TO performed on the robot combining legs and wheels. } \\
\text { - The optimization problem formalized to be solved online using } \\
\text { predictive control strategies. } \\
\text { - The method used is robust against unpredicted disturbances. }\end{array}$ \\
\hline
\end{tabular}

\section{Trajectory Optimization System Description}

Generally speaking, the problem of finding the optimal trajectory defined as the search process for the quixotic path of the system that expressed in terms of continuous parameters using collocation of arithmetic models [24]. Trajectory optimization problem divided in terms of the mathematic formulated type into optimal control model as [45] and alternative formulations mainly solved using heuristic algorithms. However, Trajectory planning problem overwhelmingly treated as an open control problem interested in detecting the superior options for control function in which the control subject only to the time.

\subsection{Problem Statement}

The general form of the objective statement of the path planning program stated in the subsequent equation

$$
f(u, s(u), c(u))=f_{1}\left(u_{I}, u_{F}, s\left(u_{I}\right), s\left(u_{F}\right)\right)+\int_{u_{I}}^{u_{F}} f 2(\tau, s(\tau), c(\tau)) \cdot d \tau
$$

The objective statement characterizes the eligible path, it possesses two main portions, the first function statement part $\mathrm{f}_{1}$ known as boundary statement describes the quality of the trajectory for the particular beginning and termination point. The second term illustrates a quantum varying over the path, mainly the integration of the engine torque. In the Equation (1), the decision variables $\mathrm{u}_{\mathrm{I}}$ and $\mathrm{u}_{\mathrm{F}}$ represent the time at the beginning and the end of the trajectory, while the functions $s(u)$ and $c(u)$ illustrates the state of the dynamic system and the control as a function of time respectively. We can observe that the purpose statement has two continuous time functions as decision variables. Subsequently, the min- 
imization process happens over the space of functions making the optimization of the trajectory generation a difficult task. In control theory, the statement shown in Equation (1) referred as a cost function.

129 130 131

\subsection{Constraints system}

The statement of purpose function described in equation (1) has a system of constraints consists of 7 inequalities and 1 equality called state equation in control theory references. However, the various applications that employ the trajectory optimization algorithms use all or part of them. The constraints are described in the following table

Table 4: The system of constraints that the main objective statement

\section{Constraints}

\section{Description}

$$
\begin{gathered}
\mathrm{J}\left(\mathrm{u}_{\mathrm{I}}, \mathrm{u}_{\mathrm{F}}, \mathrm{s}(\mathrm{u}), \mathrm{c}(\mathrm{u})\right) \leq 0 \\
\mathrm{u}_{\mathrm{L}} \leq \mathrm{u}_{\mathrm{I}}<\mathrm{u}_{\mathrm{F}} \leq \mathrm{u}_{\mathrm{H}} \\
\mathrm{s}\left(\mathrm{u}_{\mathrm{I}}\right)_{\min } \leq \mathrm{s}\left(\mathrm{u}_{\mathrm{I}}\right) \leq \mathrm{s}\left(\mathrm{u}_{\mathrm{I}}\right)_{\max } \\
\mathrm{s}\left(\mathrm{u}_{\mathrm{F}}\right)_{\min } \leq \mathrm{s}\left(\mathrm{u}_{\mathrm{F}}\right) \leq \mathrm{s}\left(\mathrm{u}_{\mathrm{F}}\right)_{\max } \\
\dot{\mathrm{s}}(\mathrm{u})_{\mathrm{m}}=\mathrm{p}(\mathrm{u}, \mathrm{s}(\mathrm{u}), \mathrm{c}(\mathrm{u})) \\
\mathrm{k}(\mathrm{u}, \mathrm{s}(\mathrm{u}), \mathrm{c}(\mathrm{u})) \leq 0 \\
\mathrm{~s}(\mathrm{u})_{\min } \leq \mathrm{s}(\mathrm{u}) \leq \mathrm{s}(\mathrm{u})_{\max } \\
\mathrm{c}(\mathrm{u})_{\min } \leq \mathrm{c}(\mathrm{u}) \leq \mathrm{c}(\mathrm{u})_{\max }
\end{gathered}
$$

Nonlinear inequality constraint on boundary Start and end time inequality boundary Premier configuration inequality constraint Ultimate configuration inequality constraint Continual dynamic equality constraint Constraints placed along the path Continual constraint on the configuration Continual constraint on the control

\subsection{Transcription Techniques}

Providing a solution to the trajectory generation problem involves special operations called transcription processes ensure changing the continuous shape functions of the problem statement into another form of a finite set of variables. Whatever these processes are, they fall into a major picture includes two central classes called direct and indirect methods.

\subsubsection{Indirect methods}

consider the following objective function

$$
\mathrm{f}\left(\mathrm{u}_{\mathrm{F}}, \mathrm{s}\left(\mathrm{u}_{\mathrm{F}}\right)\right)
$$

Given that, the condition at the initial time $\mathrm{s}\left(\mathrm{u}_{\mathrm{I}}\right)$ is known. We need to find the control $\mathrm{c}(\mathrm{u})$ that makes the objective function optimal, such that the control function subject to the dynamic constraint

$$
\dot{\mathrm{s}}(\mathrm{u})=\mathrm{p}(\mathrm{u}, \mathrm{s}(\mathrm{u}), \mathrm{c}(\mathrm{u}))
$$

And boundary conditions

$$
\mathrm{J}\left(\mathrm{u}_{\mathrm{F}}, \mathrm{s}\left(\mathrm{u}_{\mathrm{F}}\right), \mathrm{c}\left(\mathrm{u}_{\mathrm{F}}\right)\right)=0
$$

We can observe clearly that the control function and the state function must satisfy the dynamic constraint over the time interval $\mathrm{u}_{\mathrm{I}} \leq \mathrm{u} \leq \mathrm{u}_{\mathrm{F}}$. That what makes the control optimization problem different than the conventional optimization. Now, we can consider the explanation of the Lagrange multiplier to formulate the following preference

$$
\hat{\mathrm{f}}=\left[\mathrm{f}+\delta_{1}^{\mathrm{T}} \mathrm{J}\right]_{\mathrm{u}=\mathrm{u}_{\mathrm{F}}}+\int_{\mathrm{u}_{\mathrm{I}}}^{\mathrm{u}_{\mathrm{F}}} \delta_{2}^{\mathrm{T}}(\mathrm{u})\{\dot{\mathrm{s}}(\mathrm{u})-\mathrm{p}(\mathrm{u}, \mathrm{s}(\mathrm{u}), \mathrm{c}(\mathrm{u}))\} \cdot d \mathrm{u}
$$

In equation (5), $\delta_{1}$ is the Lagrange variable for the boundary constraint, while $\delta_{2}(\mathrm{u})$ is the Lagrange multiplier for dynamic constraint, commonly mentioned as costa variable. To define the optimality, the following conditions must be satisfied

40

41

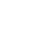

50

5
5
57




$$
\dot{\delta_{2}}=-\mathrm{H}_{\mathrm{S}}^{\mathrm{T}}
$$

And

$$
-\mathrm{H}_{\mathrm{C}}^{\mathrm{T}}=0
$$

The conditions in the set of equations (6) and (7) are derived based on the definition of Hamiltonian [34] and mostly mentioned as costa equations and control equations respectively. In previous equations, $\mathrm{H}_{\mathrm{S}}$ and $\mathrm{H}_{\mathrm{C}}$ represent the partial derivatives in terms of Hamiltonian.

$$
H=\delta_{2}^{T} p(u, s(u), c(u))
$$

Another set of conditions should be fulfilled called transversely conditions as follows

$$
\begin{gathered}
\delta_{2}\left(\mathrm{u}_{\mathrm{F}}\right)=\left[\mathrm{f}+\delta_{1}^{\mathrm{T}} \mathrm{J}\right]_{\mathrm{S}}^{\mathrm{T}} \mathrm{u}_{\mathrm{u}=\mathrm{u}_{\mathrm{F}}} \\
0=\left[\left[\mathrm{f}+\delta_{1}^{\mathrm{T}} \mathrm{J}\right]_{\mathrm{u}}+\mathrm{H}\right]_{\mathrm{u}=\mathrm{u}_{\mathrm{F}}} \\
\delta_{2}\left(\mathrm{u}_{\mathrm{I}}\right)=0
\end{gathered}
$$

Essentially, the concept of the indirect methods based on generate and derive the required and adequate conditions for optimal trajectory problem, the costa and the control equation in Equation (6) and (7) in addition to the transversely conditions (9), (10) and (11). Posteriorly, apply one of the numerical discretization algorithms on the previously mentioned necessary conditions along with the state equations, boundary condition and other system constraints such as path constraints is required. Lastly, the optimality may be found using some of nonlinear optimization algorithms.

\subsubsection{Direct methods}

The concept of direct methods established on applying some numerical analysis in order to discretize the cost function in addition to the accompanying constraints directly with no need to find any of costa, control or transversely conditions. Subsequently, we can perform nonlinear program algorithms to find the required optimality. For more detailed information, reviewing [24] is highly recommended.

\subsubsection{Direct methods against Indirect methods}

The indirect methods invented formerly by the Russian scientist Lev Pontryagin in 1956 [35] and has made a quantum leap in the applications of space manufacturing due to its high precision. However, despite its super accurate results, its implementation showed great difficulties. Here are some awkwardness, the process of finding the partial derivatives of Hamiltonian $\mathrm{H}_{\mathrm{S}}$ and $\mathrm{H}_{\mathrm{C}}$ stands a clear challenge and a difficult task. Moreover, indirect method is showing a great inflexibility, deriving all the equations and conditions are required each time we need pose the problem. There are other difficulties for this method mentioned in literatures. An indirect method is used mainly in space science. In contrast, direct methods are relatively modern and has a high degree of flexibility and strength. However, direct methods are less precise than its predecessor and not suitable for applications that required very high degrees of sensitivity such as launching a spacecraft into space. In the field of robot's application, direct methods are very suitable and sufficient.

\section{Solution Techniques}

Whether the transcription method is direct or indirect, the discretization is done using one of these two algorithms; shooting methods and collocation methods. Shooting methods depend on simulation generally Explicit Runge-Kutta integration scheme such 
as Heun's method. Collocation methods depends on function approximation generally implicit Runge-Kutta integration scheme such as trapezoidal methods. Direct methods sometimes handled as a dynamic program. Shooting methods sectioned into two main categories; single shooting simulates the entire trajectory and multiple shooting which segments the trajectory into several shorter paths. The collocation methods could be varied in terms of using the spline interpolation schemes that represent the trajectory. The global collocation use High-order splines to represent the entire trajectory different from local colocation that could use spline of a different order to represent each segment of the trajectory. Moreover, Dynamic programming could be used to solve the OC problem, it does not clearly distinct the transcription and the optimization. As an alternative, it does a system of iterative onward and backward passes along the trajectory. The following figure represent the Framework of the procedures stated for solve the trajectory optimization problems

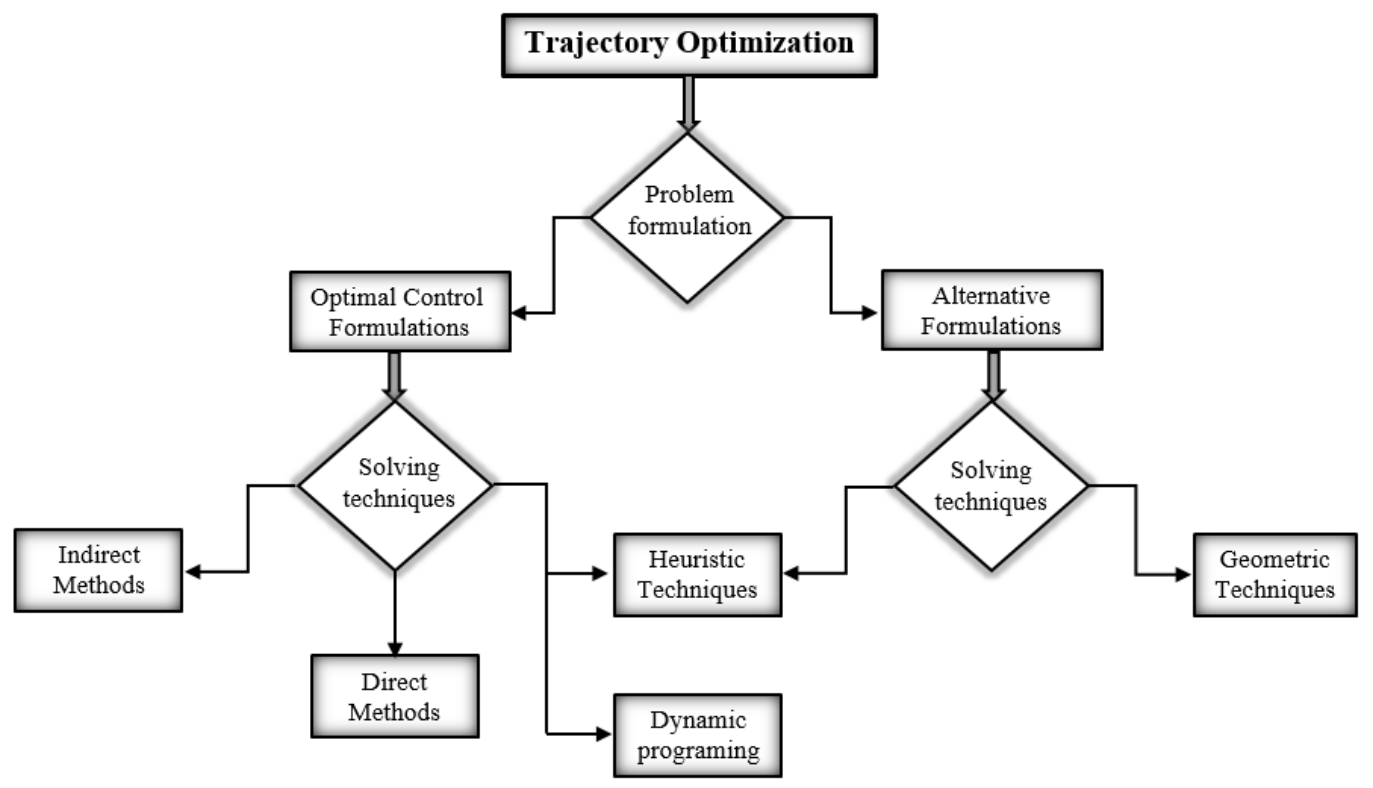

Figure 1. Schematic of the Trajectory Optimization System

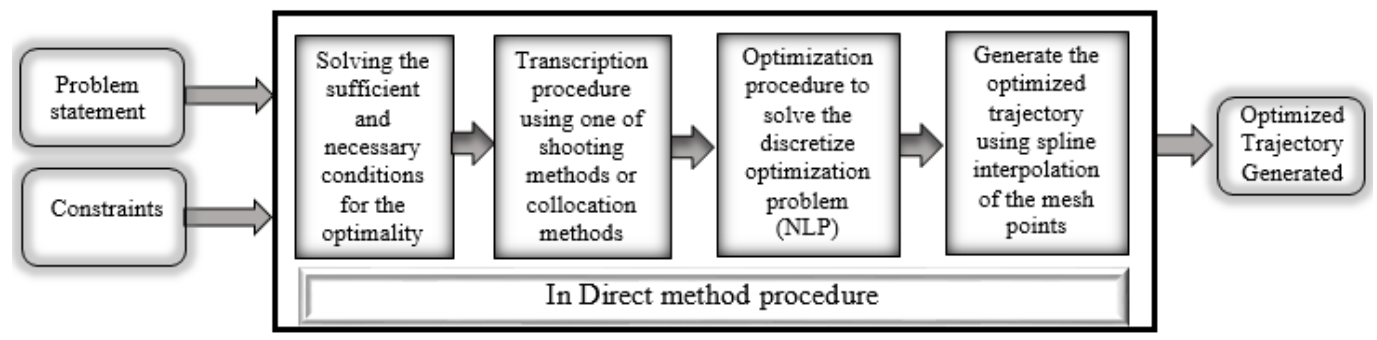

Figure 2. Diagram of the indirect method procedure

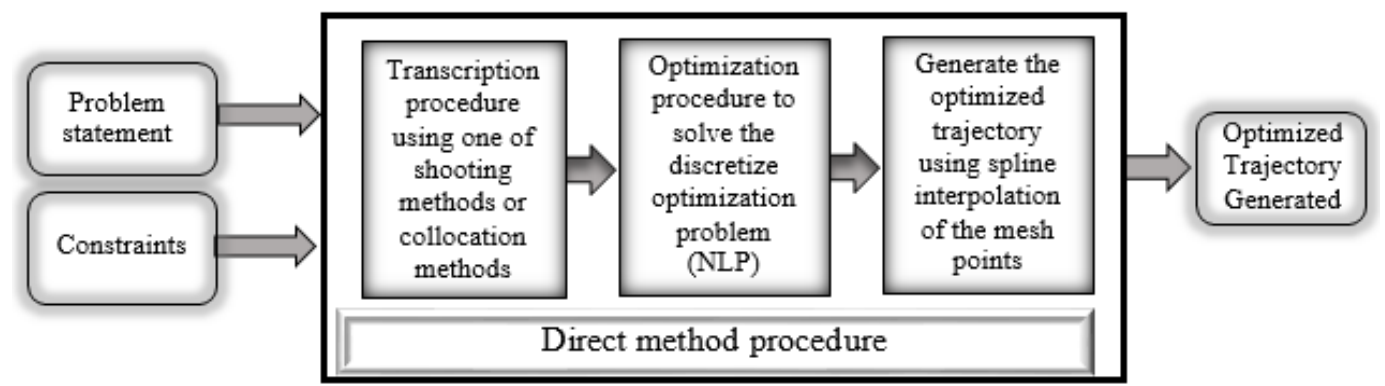

Figure 3. Schematic of the direct method procedure 


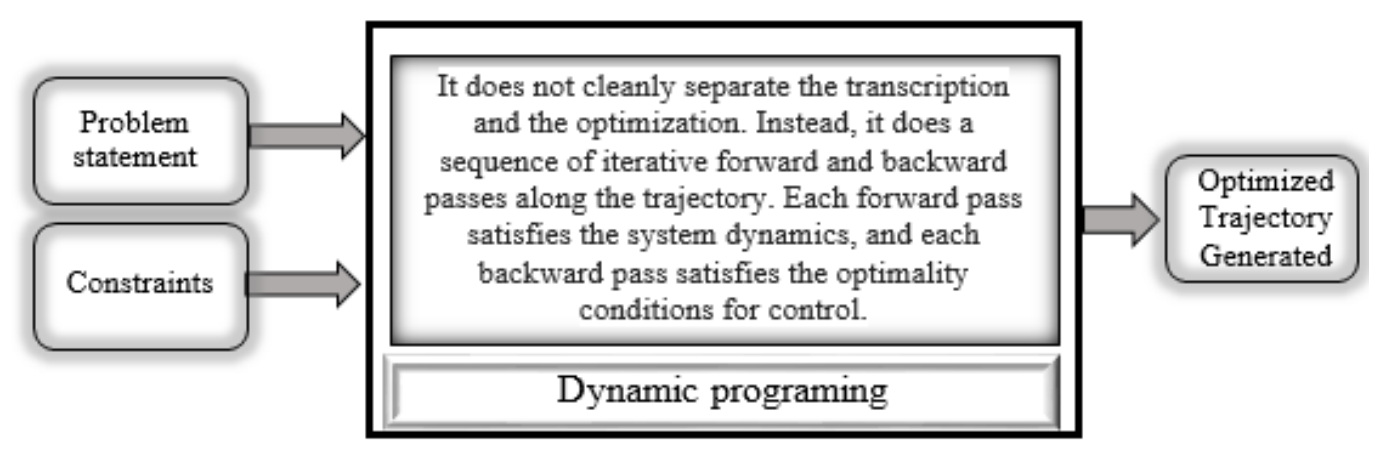

Figure 4. Schematic of the Dynamic programming

The following table describes the trajectory optimization procedure regarding several recent trajectory optimization researches in the field of the robot application

\begin{tabular}{|c|c|}
\hline References & Trajectory optimization procedure \\
\hline Glorieux et al (2018) & $\begin{array}{l}\text { - Minimize the cycle time and energy consumption. } \\
\text { - A novel methodology proposed to solve the TO problem. } \\
\text { - TO problem formulated using alternative techniques. } \\
\text { - AMPL software used to optimize the problem after transcription procedure. }\end{array}$ \\
\hline Liu et al (2017) & $\begin{array}{l}\text { - TO problem formulated as an optimal control problem. } \\
\text { - Slack convex feasible set method (SCFS) proposed to handle TO problem. } \\
\text { - Minimize computation time and convergence faster. }\end{array}$ \\
\hline Mo et al (2015) & $\begin{array}{l}\text { - A new biogeography PSO algorithm proposed } \\
\text { - Finding the optimality of the paths by AVBN. }\end{array}$ \\
\hline Kala et al (2012) & $\begin{array}{l}\text { - Solve the TO problem using Dynamic program. } \\
\text { - Dynamic obstacles considered. } \\
\text { - Additional processing called acceleration nodes to modify the result. }\end{array}$ \\
\hline Abele et al (2016) & $\begin{array}{l}\text { - Minimize the deburring process for industrial robot. } \\
\text { - Proposed technique based on } \mathrm{A}^{*} \text { to find the optimal path. } \\
\text { - TO problem transferred to salesman problem. } \\
\text { - OpenRAVE matlab interface used to solve salesman problem. }\end{array}$ \\
\hline Roy et al (2016) & $\begin{array}{l}\text { - EEG controlled robotic arm considered. } \\
\text { - GA proposed to solve TO of the EEG arm. } \\
\text { - The simulated arm simulated using GA in Matlab platform. }\end{array}$ \\
\hline Wang et al (2015) & $\begin{array}{l}\text { - Trajectory generating technique for free-floating type planetary robot. } \\
\text { - } 7 \text { (DOF) redundant manipulator considered. } \\
\text { - PSO is stated to solve the TO problem. }\end{array}$ \\
\hline Paes et al (2014) & $\begin{array}{l}\text { - Direct method for optimal control } \\
\text { - Sequential quadratic program algorithm used for the optimality }\end{array}$ \\
\hline Abu-Dakka et al (2013) & $\begin{array}{l}\text { - SSGA stated to optimize the path between } 2 \text { neighboring positions } \\
\text { - PGA to optimize a sequence of neighboring positions } \\
\text { - Clamped cubic spline aims to subject the various constraints }\end{array}$ \\
\hline Gasparetto et al (2010) & $\begin{array}{l}\text { - An inverse kinematics process to find sequence of joint sequence. } \\
\text { - SQP algorithm works for the optimality } \\
\text { - Cubic spline algorithm and b-spline are selected to construct the path }\end{array}$ \\
\hline Jin et al (2015) & $\begin{array}{l}\text { - The TO have done by minimizing the observation matrix } \\
\text { - Hadamard's relation to represent the trajectory } \\
\text { - The trajectory represented as a finite sum of sinusoidal function } \\
\text { - Dynamic constraints handled using weighted least square algorithm. }\end{array}$ \\
\hline Valente et al (2017) & - Starting and ending points of the trajectory are known. \\
\hline
\end{tabular}




\begin{tabular}{|c|c|}
\hline & $\begin{array}{l}\text { - Generate several paths and then chose the best } \\
\text { - The optimality based on Sine-jerk motion and kinematic limits }\end{array}$ \\
\hline Gleeson et al (2016) & $\begin{array}{l}\text { - Initial guess is given using a via points algorithm } \\
\text { - Robot studio ABB RABID to find the optimal time for the trajectory }\end{array}$ \\
\hline Gasparetto et al (2007) & $\begin{array}{l}\text { - Novel trajectory generation presented } \\
\text { - Discretize the optimization problem } \\
\text { - SQP optimization process performed for the optimal results } \\
\text { - Interpolation process have done using B-spline algorithm }\end{array}$ \\
\hline Gregory et al (2012) & $\begin{array}{l}\text { - TO formulated as conventional unconstrained problem. } \\
\text { - Euler-Lagrange algorithm used to solve the optimization problem. }\end{array}$ \\
\hline Böck et al (2016) & $\begin{array}{l}\text { - Discretize the path into segments describe the position and orientation } \\
\text { - The optimization at each segments using matlab function (fmincon). }\end{array}$ \\
\hline Wu et al (2016) & $\begin{array}{l}\text { - Direct method for optimal control problem } \\
\text { - Genetic algorithm is used. }\end{array}$ \\
\hline Shareef et al (2014) & $\begin{array}{l}\text { - Nonlinear variation used to formulate a TO problem. } \\
\text { - Convex programing used for optimization. }\end{array}$ \\
\hline Hassan et al (2017) & $\begin{array}{l}\text { - Dynamic side of the TO problem handled using calculus of variation } \\
\text { - GA performed to obtain the optimal path between two configurations }\end{array}$ \\
\hline Kucuk (2017) & $\begin{array}{l}\text { - Particle swarm optimization to allocate the optimum result } \\
\text { - Cubic spline interpolation used }\end{array}$ \\
\hline Števo et al (2014) & $\begin{array}{l}\text { - Minimize power consumption by the joint actuators. } \\
\text { - Parabolic trajectory discretizing } \\
\text { - Two evolutionary algorithm based are applied } \\
\end{array}$ \\
\hline Elshabasy et al (2017) & $\begin{array}{l}\text { - The dynamic parameters are discretized } \\
\text { - Genetic algorithm applied on two different objective functions. }\end{array}$ \\
\hline Cao et al (2016) & $\begin{array}{l}\text { - The dynamic configuration is handling using Lagrange multiplier. } \\
\text { - PSO performed, the result applied as an initial guess for (IPM) } \\
\text { - IPM is the interior point method }\end{array}$ \\
\hline Hank (2016) & $\begin{array}{l}\text { - Hybrid method presented } \\
\text { - Reactive navigation procedure and near optimal time TO simulation. }\end{array}$ \\
\hline Haddad et al (2007) & $\begin{array}{l}\text { - Handle the problem of existing the dynamic configuration } \\
\text { - Simulated annealing algorithm is used to find the optimal result }\end{array}$ \\
\hline Walambe et al (2016) & $\begin{array}{l}\text { - B spline approximation algorithm is used for segment the path } \\
\text { - Flatness of derivation is used to obtain the optimal results }\end{array}$ \\
\hline Celeste et al (2009) & $\begin{array}{l}\text { - Calculus of variation used to handle the dynamic property. } \\
\text { - Cross Entropy algorithm utilized to recognize the optimal solution }\end{array}$ \\
\hline Pandey et al (2017) & $\begin{array}{l}\text { - A fuzzy logic controller used for trajectory planning. } \\
\text { - Evolutionary based wind driven applied as feedback on the controller }\end{array}$ \\
\hline Kalmár-Nagy (2016). & $\begin{array}{l}\text { - Dynamic of inversion used to handle the dynamic properties } \\
\text { - Path optimal solutions has done using SNOPT function }\end{array}$ \\
\hline Li et al (2015) & $\begin{array}{l}\text { - IPM-based algorithm to solve the problem of optimal control. } \\
\text { - Hamiltonian conditions is used }\end{array}$ \\
\hline Gilimyanov et al (2008) & $\begin{array}{l}\text { - Improvement on B-spline approximation to suit the path curvature } \\
\text { - The discretized problem uses SQP algorithm to find the optimality. }\end{array}$ \\
\hline Marko et al (2020) & $\begin{array}{l}\text { - The optimization problem formalized to be solved online using predictive control } \\
\text { strategies. } \\
\text { - The method used is robust against unpredicted disturbances. }\end{array}$ \\
\hline Poya et al (2020) & $\begin{array}{l}\text { - A standard robust passivity based control approach is used for optimal trajectories } \\
\text { tracking. } \\
\text { - The optimization problem modeled to find point-to point trajectories maximizing } \\
\text { energy. }\end{array}$ \\
\hline Hui et al (2019) & - Ant colony optimization algorithm used for the optimality \\
\hline
\end{tabular}




\begin{tabular}{|c|c|}
\hline & $\begin{array}{l}\text { - Turning point optimization algorithm proposed to solve the trajectory optimization } \\
\text { - For easier tracking control of the mobile robot B-spline path smoother is presented. }\end{array}$ \\
\hline Jan et al (2019) & $\begin{array}{l}\text { - The optimization solver has the ability to freely evolution between open, closed, and } \\
\text { sliding contact states along the path. } \\
\text { - The trajectory optimization method can detect stepping motions without predefined } \\
\text { contact schedule }\end{array}$ \\
\hline Luke et al (2021) & $\begin{array}{l}\text { - The approach susceptible to uncertainty } \\
\text { - The uncertainty modeled from the terrain and the corresponding risk-sensitive } \\
\text { objectives handled for contact-implicit trajectory optimization. }\end{array}$ \\
\hline Amir et al (2019) & - Orthogonal Collocation used for trajectory optimization \\
\hline Yvain et al (2019) & $\begin{array}{l}\text { - Solve components of the base and the feet trajectories based on a linear formulation of } \\
\text { the zero moment point balance criterion } \\
\text { - The optimizer based on quadratic programming }\end{array}$ \\
\hline Romeo et al (2018) & $\begin{array}{l}\text { - Feasibility factor adapted based on Wrench Polytope (AWP) and the Feasible Wrench } \\
\text { Polytope (FWP) to improve the the process of trajectory optimization }\end{array}$ \\
\hline Wolfgang et al (2020) & $\begin{array}{l}\text { - Harmonic potential field used for collision avoidance } \\
\text { - Dynamic obstacle avoidance considered }\end{array}$ \\
\hline In-Seok et al (2019) & $\begin{array}{l}\text { - The control input generated by capture point method } \\
\text { - Sliding mode controller used to follow the zero moment point }\end{array}$ \\
\hline Riccardo et al (2019) & $\begin{array}{l}\text { - Guaranteed Sequential Trajectory Optimization algorithm is proposed to solve } \\
\text { trajectory optimization problems for control-affine systems with drift. }\end{array}$ \\
\hline Michael et al (2020) & $\begin{array}{l}\text { - Differential geometric approach for optimizing trajectories proposed on a Riemannian } \\
\text { manifold with obstacles. Hence, The optimization problem based on a metric and } \\
\text { collision function }\end{array}$ \\
\hline Zachary et al (2018) & $\begin{array}{l}\text { - The trajectory optimization done by direct transcription with ellipsoidal disturbances } \\
\text { and linear feedback algorithm using approximate invariant funnels along the trajectory }\end{array}$ \\
\hline
\end{tabular}

\section{Design Objectives of the Trajectory Optimization in robotic applications}

Finding the best solutions that optimize the design objectives considered as the main purpose of the optimization processes. However, regarding the trajectory optimization in robotic application, one can observe three main design objectives. Some researches concerning single objective, but the most studies consider multi-objective design. In what follows, there is a description of the most used design objectives of the trajectory optimization in robotic field. Minimizing the time that required to execute some task or to displace the hand frame of the robot from one place to the other considered one of the most used design objectives of the trajectory optimization in robotic application are:

1. Minimize the energy consumed during the displacements: among the most used design objectives of the trajectory optimization in robotic application;

2. Minimize the total execution time: Minimizing the time that required to execute some task or to displace the hand frame of the robot from one place to the other considered one of the most used design objectives of the trajectory optimization in robotic application;

3. Minimize the Jerk of the robot actuator: In robotic field, the jerk of the robot thought as one of the most problem facing some kind of the problem. Subsequently, minimizing the jerk is very important to retain the stability of the robot;

4. Minimize the Path length: One of the most important design objective in the field of the mobile robots;

5. Minimizing the Joint rotation: in some cases, especially in manipulator it is important to minimize the rotation of the joint in order to make the path less power consuming;

6. Minimize the Fuel Consumption: crucial characteristics in case of aerospace robots; 
7. Maximize the Clearance of the obstacles: when the trajectory planning system consider the holonomic constraints, make the obstacles more observable to the vision system is very important;

Table 6. Typical Design Objectives

\begin{tabular}{|c|c|c|c|}
\hline Objective & Units & References & Remarks \\
\hline \multirow{7}{*}{ TYPE-1 } & \multirow{5}{*}{ Joule } & Paes et al & $\begin{array}{l}\text { Dynamic model used to find energy-optimal trajectory so that the } \\
\text { energy consumption measured for pick-place motion. }\end{array}$ \\
\hline & & Elshabasy et al & \multirow{4}{*}{ Minimize the power consumption of motor joints } \\
\hline & & De Magistris et al & \\
\hline & & Gadaleta et al & \\
\hline & & Pellegrinelli et al & \\
\hline & \multirow{2}{*}{ NM } & Gleeson et al & \multirow{2}{*}{ Torques utilized as an estimator of the consumed power } \\
\hline & & Koch et al & \\
\hline \multirow{9}{*}{ TYPE-2 } & \multirow{9}{*}{ Sec } & Abu-Dakka et al & An indirect technique utilized to find the optimality. \\
\hline & & Gasparetto et al & Presetting of the execution time is required. \\
\hline & & Jin et al & Hadamard's inequality is used to define the objective function \\
\hline & & Valente et al & The minimization by a novel multivariable optimization approach \\
\hline & & Böck et al & The execution time minimized along the trajectory \\
\hline & & Shareef et al & $\begin{array}{l}\text { Optimal time trajectory whereas satisfying all the torques } \\
\text { constraints }\end{array}$ \\
\hline & & Kucuk & Minimize the time-optimal trajectory for serial and parallel robot. \\
\hline & & De Magistris et al & \multirow{2}{*}{ Minimize the time-optimal trajectory } \\
\hline & & Li et al & \\
\hline \multirow{3}{*}{ TYPE-3 } & \multirow{3}{*}{$\mathrm{mm} / \mathrm{s}^{3}$} & Gasparetto et al & $\begin{array}{l}\text { Low-jerk trajectories could be performed more swiftly and } \\
\text { precisely. }\end{array}$ \\
\hline & & Wu et al & \multirow{2}{*}{ The jerk defined as root mean square } \\
\hline & & Gasparetto et al & \\
\hline \multirow{3}{*}{ TYPE-4 } & \multirow{3}{*}{$\mathrm{mm}$} & Mac et al & PSO is utilized for minimizing the path length. \\
\hline & & Ulrich et al & Minimize the path length for the based inspection system. \\
\hline & & Hossain et al & Bacterial foraging optimization stated for optimality. \\
\hline TYPE-5 & Deg & Števo et al & Suitable to reduce the undesirable manipulation. \\
\hline TYPE-6 & KG & Chu et al & $\begin{array}{l}\text { The tenacity of the OC method is to lead the lander with the lowest } \\
\text { quantity of fuel consumed. }\end{array}$ \\
\hline TYPE-7 & units & Vale et al & Minimize the space of the mobile robot to the adjacent obstacles. \\
\hline
\end{tabular}

\section{Design Variables of the Trajectory Optimization in robotic applications}

Design variables is the numerical input that is permissible to change during the optimization procedure. In what follow a description of the most used design variables of the trajectory optimization in robotic field.

1. Joint Motor torque: rotation joints could be limited so that the solid can revolve only to a definite point, the motor so that will attempt to execute at a specific speed;

2. Joint Angle: defines the position and the orientation of the local reference frame of the robot at any moment;

3. Joint Velocity: very important variables when we are using the inverse kinematics through the optimization procedure of the robot;

4. Joint Acceleration: has special importance when studying the control system of the robot; 
5. Joint position: significant for defining the system of the robot;

6. Joint Jerk: allocating the jerk of the motor joint significant to minimalize the jerk of the robot;

Table 7. Typical Design Variables System

\begin{tabular}{|c|c|c|c|}
\hline Variable & Units & References & Remarks \\
\hline \multirow{6}{*}{ TYPE-1 } & \multirow{4}{*}{$\mathrm{Nm} /$ Arms } & Paes et al & \multirow{3}{*}{ The motor torques predicted by the dynamic model. } \\
\hline & & Abu-Dakka et al & \\
\hline & & Jin et al & \\
\hline & & Gleeson et al & The squared torque of each joints in the robot \\
\hline & NM & Gregory et al & Two joint Scara robot with holonomic constraint. \\
\hline & WATT & Wu et al & EAMA robot \\
\hline \multirow{4}{*}{ TYPE-2 } & \multirow{4}{*}{ Radian } & Paes et al & Dynamic model written in terms of the joint angles \\
\hline & & Abu-Dakka et al & \multirow{2}{*}{ Used to model the robot system. } \\
\hline & & Jin et al & \\
\hline & & Menasri et al & Redundant manipulator. \\
\hline \multirow[t]{2}{*}{ TYPE-3 } & \multirow[t]{2}{*}{$\mathrm{Rad} / \mathrm{sec}$} & Gasparetto et al & $\begin{array}{l}\text { The trajectories of the joints considered as a system of the kinematic } \\
\text { configurations }\end{array}$ \\
\hline & & Gasparetto et al & Used to model the robot system. \\
\hline TYPE-4 & $\mathrm{Deg} / \mathrm{sec}^{2}$ & Gasparetto et al & The kinematics of the joint considered for the trajectory \\
\hline TYPE-5 & $\mathrm{mm}$ & Valente et al & The locations of the joints in the robot chain. \\
\hline TYPE-6 & $\mathrm{rad} / \mathrm{sec}^{3}$ & Gasparetto et al & Six Joints open chain manipulator considered. \\
\hline
\end{tabular}

\section{Design Constraints of the Trajectory Optimization in robotic applications}

Constrained optimization is a procedure of minimize or maximize an objective regarding some variables in the attendance of functional or behavioral limitation on those variables. In what follow there is a description of the most used design variables of the trajectory optimization in robotic field.

1. Constraints on Joint Velocity: Place a suitable boundary on velocity of the joint could very important to ensure that the robot working in safe situation.

2. Constraints on Joint Acceleration: Avoiding some undesirable behavior, the acceleration of the joint motion bounded.

3. Constraints on Jerk: It is not appropriate to have high jerk in the robot while performing tasks. For this reason, constraints placed on the joint motor jerk.

4. Dynamic Constraint: Continual dynamic equality constraint to ensure that the dynamic system working efficiently.

5. Holonomic constraints: If the robot system considers the obstacles, the holonomic constraint should be stated.

6. Constraint Joint Torque: Maximum torque bounds on the motor interpreted as continuous bound on control.

7. Constraints on joint position: In order to avoid some singularity cases, a bound should be placed on the joint position.

Table 8. Typical Design Constraints

\begin{tabular}{clll}
\hline Constraint & Units & \multicolumn{1}{c}{ References } & \multicolumn{1}{c}{ Remarks } \\
\hline \multirow{2}{*}{ TYPE-1 } & \multirow{2}{*}{ Rad/sec } & Paes et al & $\begin{array}{l}\text { TO calculated in which the velocity doesn't overdo } 80 \% \text { of the } \\
\text { maximum joint angle }\end{array}$ \\
\cline { 3 - 4 } & & Gasparetto et al & Upper bounds on velocity are considered. \\
\hline
\end{tabular}




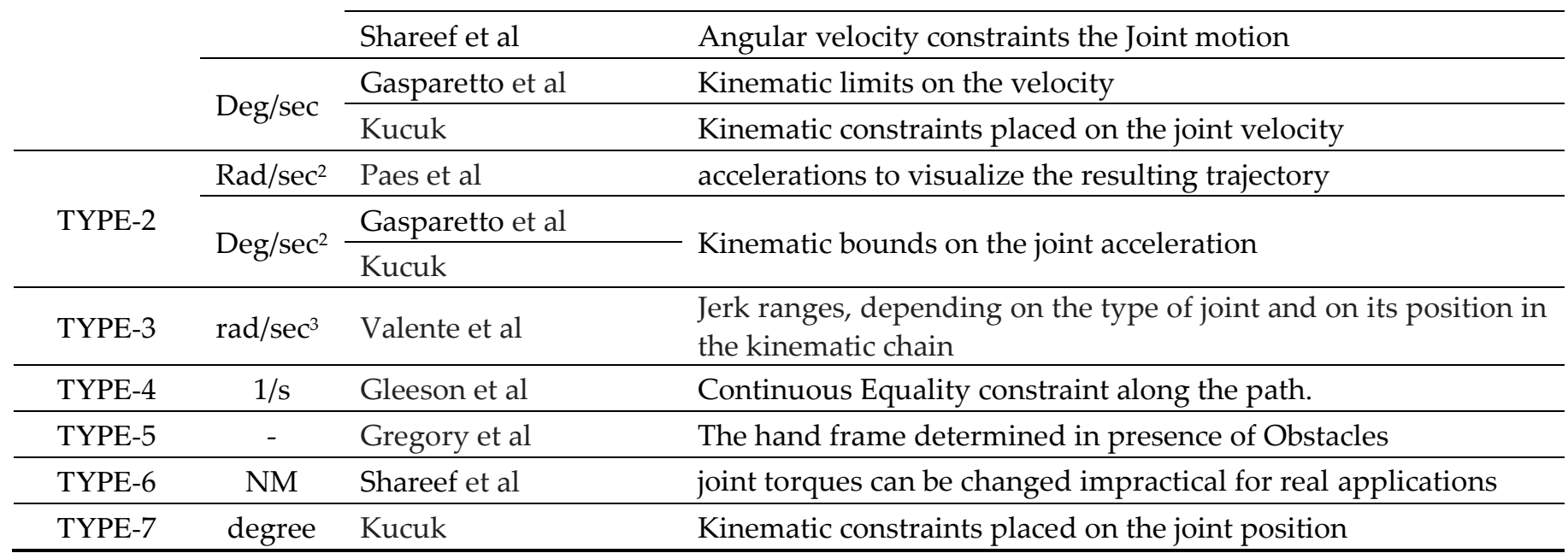

\section{Simulation Platforms used for Design the Trajectory in robotics applications}

In what follow there is a description of the most used simulation platform that used

1. Matlab: well-known multi-paradigm numerical computing environment;

2. Robot Studio: designed by ABB Company. Provides the tools to increase the profitability of the robot;

3. PSOPT simulator: respectable simulator achieves a variance, fast-moving the progress and conservation progressions of construction robots;

4. PUMA Simulator: the code is based on '3D Puma Robot Demo' from Don Riley;

5. Delmia Simulator: numerical Industrial determinations engineering invention and efficacy by preparation, simulating, and forming global assembly practices;

6. 3DCreate simulator: create complex robot models;

7. ACCADO Simulator: powerful simulator designed by ACCADO Company;

8. FEM simulator: the robot model could be computed in real-time to obtain the actuation required to orientate and position as desired;

9. IPOPT Simulator: visual studio used to simulate the robots;

Table 9. Typical Simulation Platforms

\begin{tabular}{lll}
\hline $\begin{array}{l}\text { Simulation } \\
\text { Platforms }\end{array}$ & \multicolumn{1}{c}{ References } & \multicolumn{1}{c}{ Remarks } \\
\hline \multirow{3}{*}{ TYPE-1 } & Baghli et al & TO problem solved using Ant Colony algorithm in matlab environment. \\
\cline { 2 - 3 } & Gasparetto et al & Matlab environment used to implement the simulation. \\
\cline { 2 - 3 } & Kalmár-Nagy et al & MATLAB simulation used to run SNOPT toolbox. \\
\hline TYPE-2 & Paes et al & The resultant trajectory applied in RAPID-code \\
\hline TYPE-3 & Böck et al & PSOPT simulator used to solve the optimal control problem \\
\hline TYPE-4 & Kucuk et al & Optimal Trajectory Algorithm implemented using PUMA simulator platform. \\
\hline TYPE-5 & Gadaleta et al & Automatic compute the motion parameters of the trajectory \\
\hline TYPE-6 & Ulrich et al & Robot based inspection system. \\
\hline TYPE-7 & Paes et al & IRB1600 industrial ABB robot. \\
\hline TYPE-8 & De Magistris et al & FEM simulation to model the contact e ground-sole contact. \\
\hline TYPE-9 & Li et al & Utilize IPM software platform. \\
\hline
\end{tabular}


9. Frequently used Optimization Algorithms applied to the Trajectory Optimization

In what follow there are description of the most used algorithms applied for the trajectory optimization in robotic field.

1. Sequential Quadratic Program: Iterative technique aims to solve the NOP. Functional when the objective along with the constraints are continuously differentiable;

2. Genetic algorithm: Metaheuristic stimulated by the development of regular selection to resolve complex optimization problem;

3. Dynamic Programing: This algorithm technique utilized to resolve the OC problem, it does not clearly distinct the transcription and the optimization. As an alternative, it does a system of iterative onward and backward passes along the trajectory;

4. Particle swarm optimization: Population based stochastic to solve the optimization problem;

5. Artificial Bee Colonization algorithm: $\mathrm{ABC}$ is an Optimization technique built on the foraging performance of bee swarm, utilized to solve optimization problem;

6. Artificial Ant Colony optimization algorithm: AAC is an optimization technique built on the foraging performance of ant colony, utilized to solve optimization problem;

7. Predictive Control strategies: The optimization problem formalized to be solved online using predictive controller;

Table 10. Typical Optimization Algorithms

300

301

302

303

304

305

306

307

308

309

310

311

312

313

314

315

316

317

\begin{tabular}{|c|c|c|}
\hline Algorithm & References & Remarks \\
\hline \multirow{5}{*}{ TYPE-1 } & Paes et al & ACCADO-toolkit used to solve the optimal control problem using SQP algorithm. \\
\hline & Jin et al & MATLAB Optimization toolbox Fmincon \\
\hline & Böck et al & Fmincon is used to solve the static optimization problem. \\
\hline & Gilimyanov et al & Standard SQP is used to minimize measurements errors. \\
\hline & Chen et al & SQP is used to solve optimization problem. \\
\hline \multirow{8}{*}{ TYPE-2 } & Menasri et al & Bilevel optimization technique \\
\hline & Wu et al & GA utilized to find the trajectory planning for EAMA \\
\hline & Števo et al & \multirow{3}{*}{ GA used to find the TO problem. } \\
\hline & Lim et al & \\
\hline & Sarkar et al & \\
\hline & Hassan et al & NSGA platform used to apply GA \\
\hline & Elshabasy et al & Hybrid method consisting of GA and Fmincon is utilized. \\
\hline & Oleiwi et al & Modified GA with $\mathrm{A}^{*}$ algorithm used for optimal results \\
\hline \multirow{2}{*}{ TYPE-3 } & Shareef et al & \multirow{2}{*}{ DP to solve the optimal control problem. } \\
\hline & Li et al & \\
\hline \multirow{6}{*}{ TYPE-4 } & Kucuk & PSO utilized to find the minimum time smooth trajectory. \\
\hline & Cao et al & Crossover, Mutation PSO along with interior point method \\
\hline & Jiang et al & PSO applied to find the MIRS optimization problem \\
\hline & Mac et al & PSO used to resolve the TO problem \\
\hline & Das et al & An enhanced PSA is used for multiple-robots. \\
\hline & Asma et al & Dynamic Distributed PSO used to find the optimality. \\
\hline TYPE-5 & Gupta et al & $\begin{array}{l}\text { Artificial Bee Colonization algorithm showed the best result for MIRS medical } \\
\text { robot. }\end{array}$ \\
\hline TYPE-6 & Hui et al & $\begin{array}{l}\text { Ant colony optimization algorithm used in this research so that easier tracking } \\
\text { control of the mobile robot B-spline path smoother is presented. }\end{array}$ \\
\hline
\end{tabular}


TYPE-7 Marko et al The method used is robust against unpredicted disturbances.

\section{Discussion}

Robotic applications have been greatly enhanced by the use of the trajectory optimization technologies. In this research we reviewed many of the most recent trajectory optimization techniques that used in the field of the robotic applications. However, Stationary robots including industrial and manipulator, mobile robots and walking robots got super attention.

Concerning the stationary robot, we note that the most prominent discussion topics are how we can design a robotic trajectory with optimal energy efficiency, implementation time and the jerk of the robot. The authors in [15] used the indirect method OC problem to find the optimality of the power consumed path of the two revolute planar robot in 2012. In [36] the writers utilized the ACCADO-toolkit for trajectory optimization. The trajectory optimization problem solved as a dynamic problem in [18]. [21] A method is proposed to solve the trajectory optimization formulated as non-optimal control problem by utilizing Genetic algorithm in 2014. The authors in [14] found a valid optimal trajectory for redundant manipulator robot. [62] TO problem solved the by converting it to salesman problem. In [16] PSOPT simulator used to solve the optimal control problem in 2016. [23] Proposed optimization using hybrid technique utilize Crossover, Mutation PSO along with interior point method. In 2017 [22] stated a Hybrid method consisting of GA and Fmincon to improve the trajectory optimization for redundant manipulators. In [60] a simulation interface in Delmia robotic environment proposed to solve TO problem. In [65] TO problem solved using Ant Colony algorithm.

One of the works in the domain of the stationary robot that could considered as a prospected task in the future is to use a modernistic interpolation technique such as trigonometric spline in order to discretize the problem. Moreover, considering the dynamic holonomic constraints in the stationary robot trajectory generation could be a prospected work. Utilizing Ant Colony optimization algorithm along with another optimization program to solve the problem of the trajectory optimization also need to test and compare with another optimization program.

With regard to mobile robots, we can notice that the most trending topics discussed as a TO problem is to solve the optimal time implementation of traveling time and to minimize the trajectory between two mobile robot locations. In [8] the authors applied Cross Entropy method to solve TO problem in 2009. Moreover, in [11] dynamic program is used to solve optimal control based scheme problem to Minimalize the execute time of the wheeled robot. Bacterial foraging optimization stated for optimize the time between two configurations in unknown dynamic environment in [63]. The authors in [7] solved the TO problem by spline based approach where

Differential flatness used to define the steer control line. The research in [10] proposed a new technique called Dynamic inversion based method to solve the TG. Dijkstra's algorithm used to find a collision-free trajectory in [48] where PSO is utilized to obtain the optimized trajectory.

In the domain of the mobile robots, the researcher is working to improve the responses to the dynamic obstacles along the path. Moreover, considering the electromagnetic constraints is considered as one of prospected work in the future.

Regarding the legged robots, we can observe clearly that the most researches focused on designing the optimal trajectory that satisfies minimum energy consumption and maximum forward velocity. Moreover, optimizing the gait of the walking robot has an especial attention. In [55] TO problem designed as an optimal control where the OC problem solved by framework MUSCODII. The authors in [56] used a sthenic criteria is used to solve the TO problem. Genetic algorithm is used to generate OT in [1]. The researchers in [53] utilized exact penalty function algorithm used to solve OC problem. The researches 
in this domain are working on enhance the ability of the walking robots to avoid the dynamic obstacles along the trajectory.

369

\section{Summary of this research}

In this research, we illustrated the most recent techniques used in the field of the robotics system that solve the trajectory optimization problem, especially in the last few years. In addition to the traditional techniques that used in the past, which solved the TO problem of the robotics system as an OC problem, many heuristic optimization techniques are used for this aim. Several new optimization hybrid techniques proposed recently gave a superiority over the traditional technique, Crossover, Mutation PSO along with interior point technique gave a remarkable enhancement in the field of the stationary robots. Moreover, a Hybrid method consisting of GA and Fmincon to solve TO problem proved to be efficient. PSO, AC and bacterial foraging optimization algorithms demonstrated competence in various trajectory optimization robotic fields. Also, many researches solved the TO problem using dynamic program. This technique developed to become dynamic inversion based which stated in 2015. Exact penalty function, Cross Entropy method, sthenic criteria and Spline based approach all achieved good results and were used several times in different fields of the robotic trajectory generation. In terms of recent TO computer platform, there are several environments stated recently, MUSCODII framework, PSOPT simulator, Delmia Simulator, 3D Create simulator, FEM simulator, IPOPT Simulator and ACCADO-toolkit used to solve TO problem. In these days, the robotic researches trying to develop the used techniques in order to achieve more stable trajectory optimization. In this meaning, the researches concerning in satisfying real-time trajectory generation technique, considering constraint systems that reflex the real environment such as dynamic holonomic and electromagnetic constraints, testing new hybrid optimization techniques aiming to improve the results and inventing new software platforms that make interaction between the user and the robot system more robust and superior. More gab highlighting considered in the table 11, where the optimization techniques, constraints, computer platforms, objective functions are illustrated.

In the table 12, several trajectory optimization techniques are illustrated in terms of the strengths and weaknesses aiming to compare recent developed trajectory optimization techniques in the field of the robotics. Further explanation details illustrate some recent researches exist in the appendix.

Table 11. Trajectory generation in robotic field gab highlighting

\begin{tabular}{|c|c|c|c|c|}
\hline & & Stationary & Wheeled & Legged \\
\hline \multirow{2}{*}{ TO Problem formulation style } & Optimal control & $\checkmark$ & $\checkmark$ & $\checkmark$ \\
\hline & Non-Optimal control & $\checkmark$ & $\checkmark$ & $\checkmark$ \\
\hline \multirow{2}{*}{ Transcription techniques } & Direct & $\checkmark$ & $\checkmark$ & $\checkmark$ \\
\hline & IN-Direct & $\checkmark$ & $\circ$ & $\circ$ \\
\hline \multirow{11}{*}{ Trajectory Optimization Techniques } & SQP & $\checkmark$ & $\checkmark$ & $\checkmark$ \\
\hline & $\overline{G A}$ & $\checkmark$ & $\checkmark$ & $\checkmark$ \\
\hline & PSO & $\checkmark$ & $\checkmark$ & $\circ$ \\
\hline & Dynamic Program & $\checkmark$ & $\checkmark$ & $\circ$ \\
\hline & $\mathrm{AC}$ & $\checkmark$ & o & o \\
\hline & Bacterial foraging & $\circ$ & $\circ$ & $\checkmark$ \\
\hline & Salesman model & $\checkmark$ & $\circ$ & $\circ$ \\
\hline & Exact penalty function & $\circ$ & $\checkmark$ & 0 \\
\hline & Dynamic inversion & $\checkmark$ & $\checkmark$ & $\circ$ \\
\hline & Spline based approach & $\checkmark$ & $\checkmark$ & $\circ$ \\
\hline & Cross Entropy & $\checkmark$ & $\checkmark$ & o \\
\hline
\end{tabular}




\begin{tabular}{|c|c|c|c|c|}
\hline & sthenic criteria & $\checkmark$ & o & $\checkmark$ \\
\hline \multirow{2}{*}{ Avoiding obstacles } & Dynamic & $\circ$ & $\checkmark$ & $\checkmark$ \\
\hline & Non Dynamic & $\checkmark$ & $\checkmark$ & $\checkmark$ \\
\hline \multirow{9}{*}{ Software Platform } & Matlab & $\checkmark$ & $\checkmark$ & $\checkmark$ \\
\hline & Robot Studio & $\checkmark$ & $\circ$ & $\circ$ \\
\hline & PSOPT simulator & $\circ$ & $\circ$ & $\checkmark$ \\
\hline & PUMA Simulator & $\checkmark$ & $\circ$ & o \\
\hline & Delmia Simulator & $\checkmark$ & $\circ$ & ○ \\
\hline & 3DCreate simulator & $\checkmark$ & $\circ$ & ○ \\
\hline & ACCADO Simulator & $\checkmark$ & $\mathrm{O}$ & ○ \\
\hline & FEM simulator & $\circ$ & O & $\checkmark$ \\
\hline & IPOPT Simulator & 0 & $\checkmark$ & 0 \\
\hline \multirow{7}{*}{ Constraints } & Constraints on Joint Velocity & $\checkmark$ & $\checkmark$ & $\checkmark$ \\
\hline & Constraints on Joint Acceleration & $\checkmark$ & $\checkmark$ & $\checkmark$ \\
\hline & Constraints on Jerk & $\checkmark$ & $\circ$ & o \\
\hline & Dynamic Constraint & O & $\checkmark$ & $\checkmark$ \\
\hline & Holonomic constraints & $\checkmark$ & $\checkmark$ & $\checkmark$ \\
\hline & Constraint Joint Torque & $\checkmark$ & $\checkmark$ & $\checkmark$ \\
\hline & Constraints on joint position & $\checkmark$ & $\mathrm{O}$ & O \\
\hline \multirow{7}{*}{ Minimization Objectives } & Energy consumed & $\checkmark$ & $\checkmark$ & $\checkmark$ \\
\hline & Total execution time & $\checkmark$ & $\checkmark$ & $\checkmark$ \\
\hline & Jerk of the robot actuator & $\checkmark$ & O & o \\
\hline & Path length & $\checkmark$ & $\checkmark$ & $\checkmark$ \\
\hline & Joint rotation & $\checkmark$ & $\checkmark$ & O \\
\hline & Fuel Consumption & $\circ$ & $\checkmark$ & o \\
\hline & Clearance of the obstacles & 0 & $\checkmark$ & 0 \\
\hline
\end{tabular}

Table 12. Explanation details illustrate some recent researches

\begin{tabular}{|c|c|c|c|c|}
\hline Technique & Highlights & Strength & Weakness & Reference \\
\hline $\begin{array}{l}\text { Non-invasive } \\
\text { identification } \\
\text { strategy for } \\
\text { industrial. }\end{array}$ & $\begin{array}{l}\text { Improve the } \\
\text { energy } \\
\text { efficiency of the } \\
\text { robot. }\end{array}$ & $\begin{array}{l}\text { Reducing the energy } \\
\text { expense up to } 5 \text { percent } \\
\text { compared to the } \\
\text { methods used by ABB } \\
\text { software }\end{array}$ & $\begin{array}{l}\text { Further research is needed to } \\
\text { integrate a robot stand-still } \\
\text { option in the optimization } \\
\text { procedure }\end{array}$ & Paes et al \\
\hline $\begin{array}{l}\text { A smooth } \\
\text { trajectory } \\
\text { generation model } \\
\text { for stationary } \\
\text { Robot. }\end{array}$ & $\begin{array}{l}\text { Minimize } \\
\text { execution time } \\
\text { of kinematic } \\
\text { chain based } \\
\text { robot }\end{array}$ & $\begin{array}{l}\text { The trajectory } \\
\text { generation method is } \\
\text { general-purpose, and } \\
\text { could be applied to any } \\
\text { type of robotic } \\
\text { kinematic chain }\end{array}$ & $\begin{array}{l}\text { Further research is needed } \\
\text { by considering signals from } \\
\text { some integrated sensors. }\end{array}$ & Valente et al \\
\hline $\begin{array}{l}\text { New method for } \\
\text { trajectory } \\
\text { planning of robot } \\
\text { manipulators }\end{array}$ & $\begin{array}{l}\text { Minimize the } \\
\text { total execution } \\
\text { time and the } \\
\text { squared jerk of } \\
\text { the manipulator }\end{array}$ & $\begin{array}{l}\text { Efficient algorithms to } \\
\text { achieve a good } \\
\text { execution time results } \\
\text { compared with another } \\
\text { procedure presented in } \\
\text { the research. }\end{array}$ & $\begin{array}{l}\text { Further works could be done } \\
\text { by testing modernistic } \\
\text { interpolation techniques } \\
\text { such as trigonometric spline. }\end{array}$ & Gasparetto et al \\
\hline $\begin{array}{l}\text { Bilevel } \\
\text { optimization } \\
\text { Trajectory } \\
\text { planning of }\end{array}$ & $\begin{array}{l}\text { Minimize the } \\
\text { manipulation } \\
\text { (displacement) } \\
\text { of the robot. }\end{array}$ & $\begin{array}{l}\text { Grant a new procedure } \\
\text { to find the optimal free } \\
\text { obstacles path for the }\end{array}$ & $\begin{array}{l}\text { Considering the mobile } \\
\text { obstacles dynamically that } \\
\text { could be found on the path }\end{array}$ & Menasri et al \\
\hline
\end{tabular}




\begin{tabular}{|c|c|c|c|c|}
\hline $\begin{array}{l}\text { redundant } \\
\text { manipulator }\end{array}$ & & $\begin{array}{l}\text { redundant } \\
\text { manipulators. }\end{array}$ & $\begin{array}{l}\text { could be a good prospective } \\
\text { work. }\end{array}$ & \\
\hline $\begin{array}{l}\text { Trajectory plan } \\
\text { optimization for } \\
\text { EAMA }\end{array}$ & $\begin{array}{l}\text { Minimize the } \\
\text { Jerk of the } 10 \\
\text { DOF serial } \\
\text { articulated robot }\end{array}$ & $\begin{array}{l}\text { This work achieved a } \\
\text { trajectory between } \\
\text { initial and final } \\
\text { configuration with } \\
\text { concussion in its lower } \\
\text { limits compared to pre- } \\
\text { optimization } \\
\text { procedure. }\end{array}$ & $\begin{array}{l}\text { Further stabilization } \\
\text { improvement is one of the } \\
\text { most important prospective } \\
\text { works in order to develop } \\
\text { the presented work. }\end{array}$ & Wu et al \\
\hline $\begin{array}{l}\text { Gripper } \\
\text { mechanism path } \\
\text { planning } \\
\text { optimization }\end{array}$ & $\begin{array}{l}\text { Minimize the } \\
\text { actuator } \\
\text { displacement of } \\
\text { the gripper } \\
\text { manipulator }\end{array}$ & $\begin{array}{l}\text { Modeling and } \\
\text { optimization the } \\
\text { trajectory of the end } \\
\text { frame of the gripper } \\
\text { manipulator }\end{array}$ & $\begin{array}{l}\text { Combine another gripper } \\
\text { features in the optimization } \\
\text { process. }\end{array}$ & Hassan et al \\
\hline $\begin{array}{l}\text { Optimization of } \\
\text { Robotic Arm } \\
\text { Trajectory Using } \\
\text { GA }\end{array}$ & $\begin{array}{l}\text { Minimize the } \\
\text { manipulation } \\
\text { time and energy } \\
\text { consumption. } \\
\end{array}$ & $\begin{array}{l}\text { The optimized } \\
\text { trajectory was relatively } \\
\text { swift and low power } \\
\text { consumption }\end{array}$ & $\begin{array}{l}\text { Another properties could be } \\
\text { integrated in order to reach } \\
\text { better results }\end{array}$ & Elshabasy et al \\
\hline $\begin{array}{l}\text { Hybrid approach } \\
\text { for autonomous } \\
\text { navigation of } \\
\text { mobile robots }\end{array}$ & $\begin{array}{l}\text { Near optimal } \\
\text { time trajectory } \\
\text { generation } \\
\text { simulation }\end{array}$ & $\begin{array}{l}\text { Achieved in propose } \\
\text { and test a new hybrid } \\
\text { trajectory tracking }\end{array}$ & $\begin{array}{l}\text { More work could be done } \\
\text { regarding outdoor } \\
\text { environment with dynamic } \\
\text { obstacles }\end{array}$ & Hank et al \\
\hline $\begin{array}{l}\text { Swift2Drift car } \\
\text { model for } \\
\text { wheeled mobile } \\
\text { robot. }\end{array}$ & $\begin{array}{l}\text { Minimize the } \\
\text { path length }\end{array}$ & $\begin{array}{l}\text { A good technique uses } \\
\text { flatness of derivation to } \\
\text { obtain the optimal } \\
\text { results. }\end{array}$ & $\begin{array}{l}\text { Outdoor environment with } \\
\text { dynamic holonomic } \\
\text { constraint will be the author } \\
\text { future work }\end{array}$ & Walambe et al \\
\hline $\begin{array}{l}\text { Smoothing } \\
\text { Curvature of } \\
\text { Trajectories } \\
\text { Constructed by } \\
\text { Noisy } \\
\text { Measurements }\end{array}$ & $\begin{array}{l}\text { Minimize the } \\
\text { variation of } \\
\text { control points }\end{array}$ & $\begin{array}{l}\text { New improvement on } \\
\text { the B-spline } \\
\text { approximation } \\
\text { algorithms to suit the } \\
\text { path curvature }\end{array}$ & $\begin{array}{l}\text { Further experiments } \\
\text { regarding another kinds of } \\
\text { physical obstacles }\end{array}$ & Gilimyanov et al \\
\hline
\end{tabular}

we can observe clearly that, the optimization trajectory in the robotic field became a trend in the last few years, where many researches are doing a great effort in order to improve the traditional trajectory optimization techniques aiming to make these algorithms more suitable for a recent types of robotics and as closer as conceivable to effort in actual time situation environment. In the following figure, summarization of the recent design and optimization methodologies for trajectory optimization in the robotic field. 


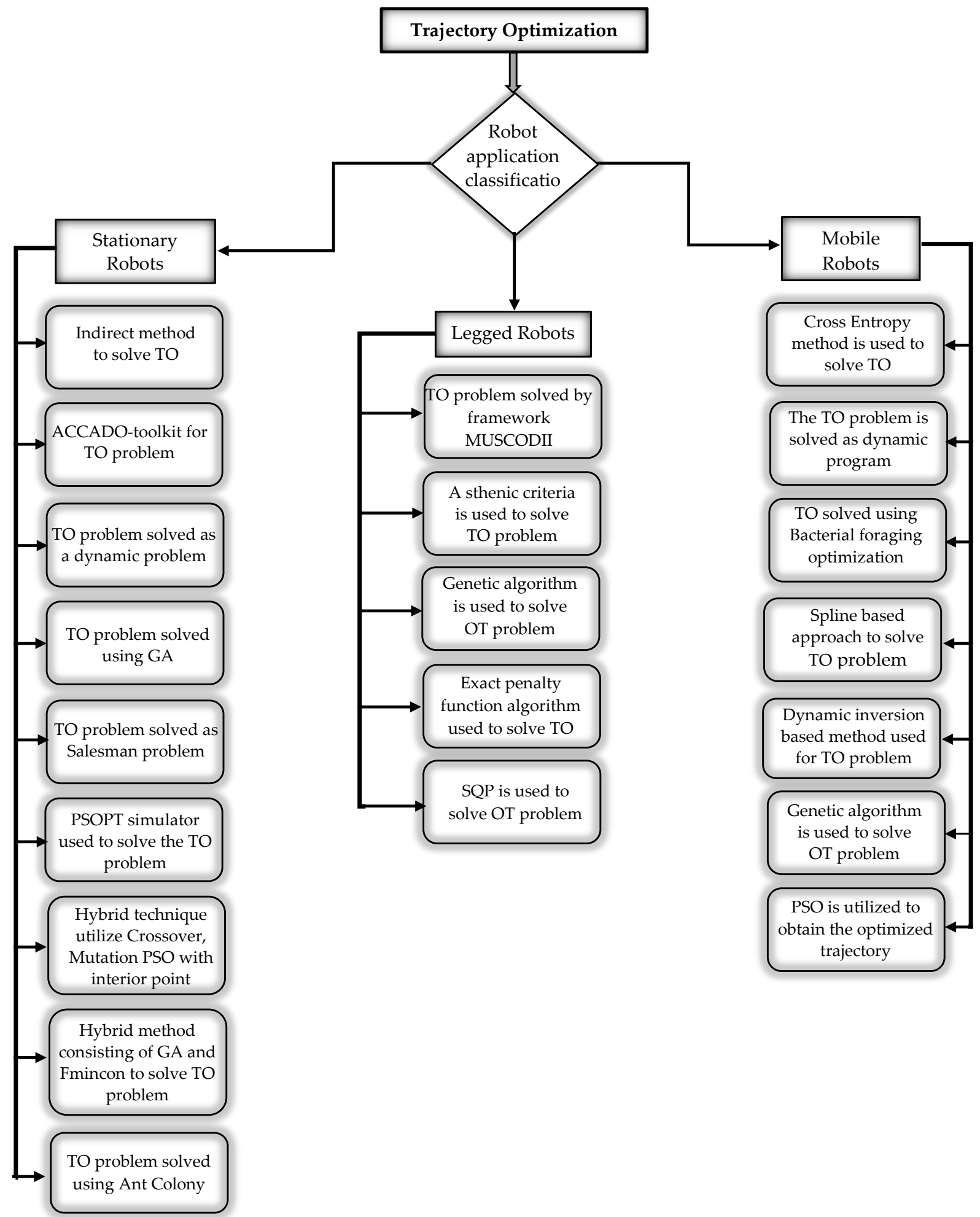

Figure 5. Recent design and optimization methodologies for Trajectory optimization in the robotic field

\section{Conclusion}

This research offers an inclusive evaluation and critical compare of the newest strategy and optimization methods of the TG in the Robotic system environment. Aiming to find the optimal Path planning in the Robotic field, various assessment parameters such as Joint Velocity, angle, acceleration and jerk are illuminated and summed up. The chosen of some of these considerations is fundamentally to achieve an optimal mixture for the 
energy expended, total execution time, Jerk of the robot and the Path length. Moreover, Dynamic and Holonomic constraints have an influence on the TO problem. According to this review, it is noticed that utilize of the Hybrid Heuristic techniques in the optimization problematic increase the precious of optimization results paralleled to utilize the Ordinary Trajectory Optimization approaches.

Most of the researches for the TO in Robotic system are accomplished based on OC methods including Heuristic and Gradient Base method. Heuristic methods has the capability to exploration for global and local optimum and offer a set of optimal consequences with a smaller amount of computational time. Also, Fusion algorithms have lately been widely practical for the Trajectory optimization of the robotic system. Moreover, software PC tools are similarly utilized broadly for scheming of Trajectory Optimization Techniques. Conversely, using recent methods such as artificial algorithms and hybrid algorithms offer more precise optimization outcomes than software tools as they have the facility to resolve multi-objective optimization problems. This research examines the key root research approaches and their equivalent applications in Robotic Trajectory optimization aiming to let more specialists recognize the present research status and also offer some directing for relevant studies.

Conflicts of Interest: The authors declare no conflict of interest;

1. Lim, I. S., Kwon, O., \& Park, J. H. (2014). Gait optimization of biped robots based on human motion analysis. Robotics and Autonomous Systems, 62(2), 229-240.

2. Cirillo, A., Cirillo, P., De Maria, G., Marino, A., Natale, C., \& Pirozzi, S. (2017). Optimal custom design of both symmetric and unsymmetrical hexapod robots for aeronautics applications. Robotics and Computer-Integrated Manufacturing, 44, 116.

3. Zhong, Q. B., \& Chen, F. (2016). Trajectory planning for biped robot walking on uneven terrain-Taking stepping as an example. CAAI Transactions on Intelligence Technology, 1(3), 197-209.

4. Kherici, N., \& Ali, Y. M. B. (2014). Using PSO for a walk of a biped robot. Journal of Computational Science, 5(5), 743-749.

5. Zhong, Q. B., \& Chen, F. (2016). A hybrid approach for autonomous navigation of mobile robots in partially-known environments. Robotics and Autonomous Systems, 86, 113-127.

6. Haddad, M., Chettibi, T., Hanchi, S., \& Lehtihet, H. E. (2007). A random-profile approach for trajectory planning of wheeled mobile robots. European Journal of Mechanics-A/Solids, 26(3), 519-540.

7. Walambe, R., Agarwal, N., Kale, S., \& Joshi, V. (2016). Optimal Trajectory Generation for Car-type Mobile Robot using Spline Interpolation This work is carried out under the research project grant sanctioned under the WOS-A scheme by Department of Science and Technology (DST), Govt. of India. IFAC-PapersOnLine, 49(1), 601-606.

8. Celeste, F., Dambreville, F., \& Le Cadre, J. P. (2009). Optimized trajectories for mobile robot with map uncertainty. IFAC Proceedings Volumes, 42(10), 1475-1480.

9. Pandey, A., \& Parhi, D. R. (2017). Optimum path planning of mobile robot in unknown static and dynamic environments using Fuzzy-Wind Driven Optimization algorithm. Defence Technology, 13(1), 47-58.

10. Kalmár-Nagy, T. (2016). Real-time trajectory generation for Omni-directional vehicles by constrained dynamic inversion. Mechatronics, 35, 44-53.

11. Li, B., \& Shao, Z. (2015). Simultaneous dynamic optimization: A trajectory planning method for nonholonomic car-like robots. Advances in Engineering Software, 87, 30-42.

12. Gilimyanov, R. F., Pesterev, A. V., \& Rapoport, L. B. (2008). Smoothing curvature of trajectories constructed by noisy measurements in path planning problems for wheeled robots. Journal of Computer and Systems Sciences International, 47(5), 812-819.

13. Gasparetto, A., \& Zanotto, V. (2007). A new method for smooth trajectory planning of robot manipulators. Mechanism and machine theory, 42(4), 455-471.

14. Menasri, R., Nakib, A., Daachi, B., Oulhadj, H., \& Siarry, P. (2015). A trajectory planning of redundant manipulators based on bilevel optimization. Applied Mathematics and Computation, 250, 934-947.

15. Gregory, J., Olivares, A., \& Staffetti, E. (2012). Energy-optimal trajectory planning for robot manipulators with holonomic constraints. Systems \& Control Letters, 61(2), 279-291.

16. Böck, M., Plainer, M., \& Kugi, A. (2016). Evaluation of Efficiently Generating Fast Robot Trajectories Under Geometric and System Constraints. IFAC-PapersOnLine, 49(21), 395-402. 
17. Wu, J., Wu, H., Song, Y., Cheng, Y., Zhao, W., \& Wang, Y. (2016). Genetic algorithm trajectory plan optimization for EAMA: EAST Articulated Maintenance Arm. Fusion Engineering and Design, 109, 700-706.

18. Shareef, Z., \& Trächtler, A. (2014). Joint selection criterion for optimal trajectory planning for robotic manipulators using dynamic programming. IFAC Proceedings Volumes, 47(3), 6025-6031.

19. Hassan, A., \& Abomoharam, M. (2017). Modeling and design optimization of a robot gripper mechanism. Robotics and Computer-Integrated Manufacturing, 46, 94-103.

20. Kucuk, S. (2017). Optimal trajectory generation algorithm for serial and parallel manipulators. Robotics and ComputerIntegrated Manufacturing, 48, 219-232.

21. Števo, S., Sekaj, I., \& Dekan, M. (2014). Optimization of robotic arm trajectory using genetic algorithm. IFAC Proceedings Volumes, 47(3), 1748-1753.

22. Elshabasy, M. M., Mohamed, K. T., \& Ata, A. A. (2017). Power optimization of planar redundant manipulator moving along constrained-end trajectory using hybrid techniques. Alexandria Engineering Journal.

23. Cao, H., Sun, S., Zhang, K., \& Tang, Z. (2016). Visualized trajectory planning of flexible redundant robotic arm using a novel hybrid algorithm. Optik-International Journal for Light and Electron Optics, 127(20), 9974-9983.

24. Betts, J. T., \& Kolmanovsky, I. (2002). Practical methods for optimal control using nonlinear programming. Applied Mechanics Reviews, 55, B68.

25. Optimal Control (2017). In Wikipedia. Retrieved from https://en.wikipedia.org/wiki/Optimal_control.html

26. Rao, A. V. (2009). A survey of numerical methods for optimal control. Advances in the Astronautically Sciences, 135(1), 497-528.

27. Brachistochrone Problem (2017). In Wolfram Matworld. Retrieved in http://mathworld.wolfram.com/BrachistochroneProblem.html

28. Gelfand, I. M., \& Silverman, R. A. (2000). Calculus of variations. Courier Corporation.

29. Trajectory Optimization (2017). In Wikipedia. Retrieved in https://en.wikipedia.org/wiki/Trajectory_optimization

30. Sridhar, B., Ng, H. K., \& Chen, N. Y. (2011). Aircraft trajectory optimization and contrails avoidance in the presence of winds. Journal of Guidance, Control and Dynamics, 34(5), 1577-1583.

31. Mellinger, D., Michael, N., \& Kumar, V. (2012). Trajectory generation and control for precise aggressive maneuvers with quadrotors. The International Journal of Robotics Research, 31(5), 664-674.

32. Hehn, M., \& D'Andrea, R. (2015). Real-time trajectory generation for quadrocopters. IEEE Transactions on Robotics, 31(4), 877-892.

33. Eaton, J. W., \& Rawlings, J. B. (1992). Model-predictive control of chemical processes. Chemical Engineering Science, 47(4), 705-720.

34. Taton, R. (1974). Inventaire chronologique de l'œuvre de Lagrange. Revue d'histoire des sciences, 3-36.

35. Boltyanskii, V. G., R. V. Gamkrelidze, and L. S. Pontryagin. "Towards a theory of optimal processes, Reports Acad." Sci. USSR 110.1 (1956): 710.

36. Paes, K., Dewulf, W., Vander Elst, K., Kellens, K., \& Slaets, P. (2014). Energy efficient trajectories for an industrial ABB robot. Procedia Cirp, 15, 105-110.

37. Abu-Dakka, F. J., Rubio, F., Valero, F., \& Mata, V. (2013). Evolutionary indirect approach to solving trajectory planning problem for industrial robots operating in workspaces with obstacles. European Journal of Mechanics-A/Solids, 42, 210218.

38. Gasparetto, A., \& Zanotto, V. (2010). Optimal trajectory planning for industrial robots. Advances in Engineering Software, 41(4), 548-556.

39. Jin, J., \& Gans, N. (2015). Parameter identification for industrial robots with a fast and robust trajectory design approach. Robotics and Computer-Integrated Manufacturing, 31, 21-29.

40. Valente, A., Baraldo, S., \& Carpanzano, E. (2017). Smooth trajectory generation for industrial robots performing high precision assembly processes. CIRP Annals-Manufacturing Technology.

41. Gleeson, D., Björkenstam, S., Bohlin, R., Carlson, J. S., \& Lennartson, B. (2016). Towards Energy optimization using trajectory smoothing and automatic code generation for robotic assembly. Procedia Cirp, 44, 341-346.

42. Gupta, S., Sarkar, S. T., \& Kumar, A. (2015). Design optimization of minimally invasive surgical robot. Applied Soft Computing, 32, 241-249.

43. Jiang, J., Xing, Y., Wang, S., \& Liang, K. (2017). Evaluation of robotic surgery skills using dynamic time warping. Computer Methods and Programs in Biomedicine, 152, 71-83.

44. De Magistris, G., Pajon, A., Miossec, S., \& Kheddar, A. (2017). Optimized humanoid walking with soft soles. Robotics and Autonomous Systems, 95, 52-63.

45. Chu, H., Ma, L., Wang, K., Shao, Z., \& Song, Z. (2017). Trajectory optimization for lunar soft landing with complex constraints. Advances in Space Research, 60(9), 2060-2076.

46. Suebsaiprom, P., \& Lin, C. L. (2015). Maneuverability modeling and trajectory tracking for fish robot. Control Engineering Practice, 45, 22-36.

47. Suebsaiprom, P., Lin, C. L., \& Engkaninan, A. (2017). Undulatory locomotion and effective propulsion for fish-inspired robot. Control Engineering Practice, 58, 66-77. 
48. Mac, T. T., Copot, C., Tran, D. T., \& De Keyser, R. (2017). A hierarchical global path planning approach for mobile robots based on multi-objective particle swarm optimization. Applied Soft Computing, 59, 68-76.

49. Das, P. K., Behera, H. S., \& Panigrahi, B. K. (2016). A hybridization of an improved particle swarm optimization and gravitational search algorithm for multi-robot path planning. Swarm and Evolutionary Computation, 28, 14-28.

50. Chen, Y. L., Cheng, J., Lin, C., Wu, X., Ou, Y., \& Xu, Y. (2013). Classification-based learning by particle swarm optimization for wall-following robot navigation. Neurocomputing, 113, 27-35.

51. Vale, A., Fonte, D., Valente, F., \& Ribeiro, I. (2014). Trajectory optimization for autonomous mobile robots in ITER. Robotics and Autonomous Systems, 62(6), 871-888.

52. Sarkar, A., \& Dutta, A. (2015). 8-DoF biped robot with compliant-links. Robotics and Autonomous Systems, 63, 57-67.

53. Sun, Z., Li, H., Wang, J., \& Tian, Y. (2015). A Gait Optimization Smoothing Penalty Function Method for Bipedal Robot via DMOC $^{* *}$ The authors would like to thank National High Technology Research and Development Program of China (863 Program), grant No. 2006AA04Z251, and The National Natural Fund Project, grant No. 60974067 and The Founds of Jilin Province Science and Technology, grant No. 2013577, 2013267, 2013287, 2014636. IFAC-PapersOnLine, 48(28), 1148-1153.

54. Aoustin, Y., \& Hamon, A. (2013). Human like trajectory generation for a biped robot with a four-bar linkage for the knees. Robotics and Autonomous Systems, 61(12), 1717-1725.

55. Koch, K. H., Mombaur, K., \& Soueres, P. (2012). Optimization-based walking generation for humanoid robot. IFAC Proceedings Volumes, 45(22), 498-504.

56. Chen, Z., Elyaaqoubi, N. L., \& Abba, G. (2016). Optimized 3D stable walking of a bipedal robot with line-shaped massless feet and sagittal underactuation. Robotics and Autonomous Systems, 83, 203-213.

57. Asma, A., \& Sadok, B. (2017). Dynamic Distributed PSO joints elites in Multiple Robot Path Planning Systems: theoretical and practical review of new ideas. Procedia Computer Science, 112, 1082-1091.

58. Oleiwi, B. K., Al-Jarrah, R., Roth, H., \& Kazem, B. I. (2015). Integrated Motion Planning and Control for Multi Objectives Optimization and Multi Robots Navigation. IFAC-PapersOnLine, 48(10), 99-104.

59. Das, P. K., Behera, H. S., Jena, P. K., \& Panigrahi, B. K. (2016). Multi-robot path planning in a dynamic environment using improved gravitational search algorithm. Journal of Electrical Systems and Information Technology, 3(2), 295-313.

60. Gadaleta, M., Berselli, G., Pellicciari, M., \& Sposato, M. (2017). A Simulation Tool for Computing Energy Optimal Motion Parameters of Industrial Robots. Procedia Manufacturing, 11, 319-328.

61. Gasparetto, A., \& Zanotto, V. (2008). A technique for time-jerk optimal planning of robot trajectories. Robotics and Computer-Integrated Manufacturing, 24(3), 415-426.

62. Ulrich, M., Lux, G., Jürgensen, L., \& Reinhart, G. (2015). Automated and Cycle Time Optimized Path Planning for RobotBased Inspection Systems. Procedia CIRP, 44, 377-382.

63. Hossain, M. A., \& Ferdous, I. (2015). Autonomous robot path planning in dynamic environment using a new optimization technique inspired by bacterial foraging technique. Robotics and Autonomous Systems, 64, 137-141.

64. Pellegrinelli, S., Borgia, S., Pedrocchi, N., Villagrossi, E., Bianchi, G., \& Tosatti, L. M. (2015). Minimization of the energy consumption in motion planning for single-robot tasks. Procedia Cirp, 29, 354-359.

65. Baghli, F. Z., \& Lakhal, Y. (2017). Optimization of Arm Manipulator Trajectory Planning in the Presence of Obstacles by Ant Colony Algorithm. Procedia Engineering, 181, 560-567.

66. SHEHATA, H. H., \& SCHLATTMANN, J. (2014). Potential field multi-objective optimization for robot path planning using genetic algorithm. Mobile Service Robotics: CLAWAR 2014, 12, 149.

67. Glorieux, E., Riazi, S., \& Lennartson, B. (2018). Productivity/energy optimisation of trajectories and coordination for cyclic multi-robot systems. Robotics and Computer-Integrated Manufacturing, 49, 152-161.

68. Liu, C., \& Tomizuka, M. (2017). Real time trajectory optimization for nonlinear robotic systems: Relaxation and convexification. Systems \& Control Letters, 108, 56-63.

69. Mo, H., \& Xu, L. (2015). Research of biogeography particle swarm optimization for robot path planning. Neurocomputing, $148,91-99$.

70. Kala, R., Shukla, A., \& Tiwari, R. (2012). Robot path planning using dynamic programming with accelerating nodes. Paladyn, Journal of Behavioral Robotics, 3(1), 23-34.

71. Abele, E., Haehn, F., Pischan, M., \& Herr, F. (2016). Time Optimal Path Planning for Industrial Robots Using STL Data Files. Procedia CIRP, 55, 6-11.

72. Roy, R., Mahadevappa, M., \& Kumar, C. S. (2016). Trajectory path planning of EEG controlled robotic arm using GA. Procedia Computer Science, 84, 147-151.

73. Wang, M., Luo, J., \& Walter, U. (2015). Trajectory planning of free-floating space robot using Particle Swarm Optimization (PSO). Acta Ast

74. Orsolino, R., Focchi, M., Mastalli, C., Dai, H., Caldwell, D. G., \& Semini, C. (2018). Application of wrench-based feasibility analysis to the online trajectory optimization of legged robots. IEEE Robotics and Automation Letters, 3(4), 3363-3370.

75. Yang, H., Qi, J., Miao, Y., Sun, H., \& Li, J. (2018). A new robot navigation algorithm based on a double-layer ant algorithm and trajectory optimization. IEEE Transactions on Industrial Electronics, 66(11), 8557-8566.

76. de Viragh, Y., Bjelonic, M., Bellicoso, C. D., Jenelten, F., \& Hutter, M. (2019). Trajectory optimization for wheeled-legged quadrupedal robots using linearized zmp constraints. IEEE Robotics and Automation Letters, 4(2), 1633-1640. 
77. He, S., Shin, H. S., \& Tsourdos, A. (2019). Trajectory optimization for target localization with bearing-only measurement. IEEE Transactions on Robotics, 35(3), 653-668.

78. Carius, J., Ranftl, R., Koltun, V., \& Hutter, M. (2019). Trajectory optimization for legged robots with slipping motions. IEEE Robotics and Automation Letters, 4(3), 3013-3020.

79. Khalaf, P., \& Richter, H. (2019). Trajectory optimization of robots with regenerative drive systems: Numerical and experimental results. IEEE Transactions on Robotics, 36(2), 501-516.

80. Bonalli, R., Cauligi, A., Bylard, A., \& Pavone, M. (2019, May). GuSTO: Guaranteed sequential trajectory optimization via sequential convex programming. In 2019 International Conference on Robotics and Automation (ICRA) (pp. 6741-6747). IEEE.

81. Bjelonic, M., Sankar, P. K., Bellicoso, C. D., Vallery, H., \& Hutter, M. (2020). Rolling in the deep-hybrid locomotion for wheeled-legged robots using online trajectory optimization. IEEE Robotics and Automation Letters, 5(2), 3626-3633.

82. Drnach, L., \& Zhao, Y. (2021). Robust trajectory optimization over uncertain terrain with stochastic complementarity. IEEE Robotics and Automation Letters, 6(2), 1168-1175.

83. Watterson, M., Liu, S., Sun, K., Smith, T., \& Kumar, V. (2020). Trajectory optimization on manifolds with applications to quadrotor systems. The International Journal of Robotics Research, 39(2-3), 303-320.

84. Merkt, W., Ivan, V., \& Vijayakumar, S. (2019, November). Continuous-time collision avoidance for trajectory optimization in dynamic environments. In 2019 IEEE/RSJ International Conference on Intelligent Robots and Systems (IROS) (pp. 72487255). IEEE.

85. Kim, I. S., Han, Y. J., \& Hong, Y. D. (2019). Stability control for dynamic walking of bipedal robot with real-time capture point trajectory optimization. Journal of Intelligent \& Robotic Systems, 96(3), 345-361.

86. Manchester, Z., \& Kuindersma, S. (2019). Robust direct trajectory optimization using approximate invariant funnels. Autonomous Robots, 43(2), 375-387.

87. Bottin, M., \& Rosati, G. (2019). Trajectory optimization of a redundant serial robot using cartesian via points and kinematic decoupling. Robotics, 8(4), 101.

606 